\title{
A TIPS Scorecard: Are TIPS Accomplishing What They Were Supposed to Accomplish? Can They Be Improved?
}

\author{
Michelle L. Barnes, Zvi Bodie, Robert K. Triest, and J. Christina Wang
}

\begin{abstract}
:
The U.S. Treasury developed the TIPS market in order to achieve three important policy objectives: (1) to provide consumers with a class of assets that allows for hedging against real interest rate risk, (2) to provide holders of nominal contracts a means of hedging against inflation risk, and (3) to provide everyone with a reliable indicator of the term structure of expected inflation. This paper evaluates progress toward the achievement of these objectives and analyzes prospective ways to better meet these objectives in the future, by, for example, extending the maturity of TIPS and/or the use of inflation indexes suited to particular geographic regions or demographics. We conclude by arguing that while it is tempting to consider completing markets by introducing more TIPS-like securities indexed to inflation rates more tailored to particular demographics, our analysis suggests that TIPS indexed to CPI do, in fact, facilitate good synthetic hedges against unexpected changes in inflation for many different investors, since the various inflation measures are very highly correlated. We do, however, argue for extending the maturity of TIPS.
\end{abstract}

\section{JEL Classifications: G10, G11, G18}

Michelle L. Barnes is a senior economist and policy advisor, Robert K. Triest is a vice president, and economist and J. Christina Wang is a senior economist at the Federal Reserve Bank of Boston. Zvi Bodie is the Norman and Adele Barron Professor of Management at Boston University. Their email addresses are, michelle.barnes@bos.frb.org, robert.triest@bos.frb.org, christina.wang@bos.frb.org, and zbodie@bu.edu, respectively.

The authors would like to thank Jeff Fuhrer for helpful discussions, and Adrienne Hathaway and Brendan Mackoff for capable research assistance.

This paper, which may be revised, is available on the web site of the Federal Reserve Bank of Boston at http://www.bos.frb.org/economic/ppdp/index.htm.

The views expressed in this paper are solely those of the authors and not necessarily those of the Federal Reserve Bank of Boston or the Federal Reserve System.

version of: March 2010; original version: September 2009 


\section{Introduction}

When the U.S. Treasury introduced TIPS in 1997, they were designed to achieve three major policy objectives. The first objective was to provide consumers with a class of assets that allows them to hedge against real interest rate risk. This required a term structure of default-free bonds denominated in consumption units. The second objective was to provide holders of nominal contracts with a way to hedge against inflation risk. This required a term structure of default free CPI-forward contracts. The third objective was to provide everyone with a reliable indicator of the term structure of expected inflation. This paper examines the extent to which these objectives have been achieved and seeks to identify ways they can be achieved better in the future. Possible future improvements we consider are the use of different inflation indexes, including those more closely matched with particular geographic regions or demographics, and extending the maturity of TIPS.

The viability of the U. S. Treasury Inflation Protected Securities (TIPS) market hinges on whether these securities provide an effective hedge for most investors against unexpected changes in the real rate of interest due to unexpected fluctuations in inflation. Such indexed bonds are designed to deliver, to the extent possible, a certain pre-tax real return to maturity. In the United States, these bonds are indexed to the Consumer Price Index for all urban consumers (CPI-U). This paper focuses on two important factors that may limit the ability of this class of securities to offer investors a complete hedge against unexpected changes in the real rate: (1) the possibility that the CPI may not be an appropriate index for all investors; and (2) the potential for technical revisions to the measurement of the CPI, such as those recommended by the Boskin Commission just before the initial auctioning of TIPS in January of 1997. Both of these factors could engender inflation basis risk. ${ }^{1,2}$ Another widely known limiting factor-the fact

\footnotetext{
1 The Treasury declared that such changes would be deemed "technical" as opposed to "fundamental" and hence would not call for a replacement series recommended by the BLS; nevertheless, they draw attention to another source of pre-tax real return uncertainty. See appendix B to Part 356 of Title 31 in the Federal Register, "Sale and Issue of Marketable Book-entry Treasury Bills, Notes, and Bonds (Department of the Treasury Circular, Public Debt Series 193) and Anderson (1999).
} 
that CPI is not continuously measured and published, with the result that the indexation of these securities' nominal cash flows occurs with some lag - will not be addressed here.

During the summer of 2008, a spate of popular press articles emerged decrying the construction of the CPI with claims that the existing methodology underestimates true inflation. An article by Kevin Phillips in the May 2008 edition of Harper's magazine went so far as to assert that the measure is subject to political influence and has been biased downward over time via methodological changes occurring during different presidential regimes. ${ }^{3}$ Since these concerns speak to fundamental uncertainties regarding the ability of TIPS to offer an effective hedge against unexpected changes in the real rate, it is not surprising that a few of these articles concluded that therefore TIPS were not, in fact, good hedges of inflation as broadly experienced by investors. ${ }^{4}$ Another criticism of TIPS that occasionally arises is the observation that breakeven inflation rates as implied by simultaneous consideration of the TIPS and nominal Treasury markets often diverge substantially from survey measures of inflation expectations. Such mounting criticisms and concerns could jeopardize the viability of the TIPS market.

This paper evaluates the premises of these criticisms, and, to the extent that there is any validity to these criticisms, assesses their implications for the efficacy of TIPS as a hedge against unexpected changes in the real rate of interest. In particular, we evaluate the criticisms centering on the accuracy of the CPI as a basis for measuring changes in the rate of inflation. In addition, given that heterogeneity exists across households, we aim to determine who benefits the most and the least from hedging with TIPS, and whether or not long-term TIPS investors are better off than short-term investors. We also explore whether or not there would be significant gains from indexing TIPS to other inflation measures. ${ }^{5}$ The divergence between inflation

\footnotetext{
2 In fact, in September 2000, the BLS announced a miscalculation of the CPI, prompting the Treasury to reopen the 2029 indexed bond "to preclude any computational issues regarding the Reference CPI that would be associated with the issuance of a new security." Please see Deacon, Derry, and Mirfendereski (2004).

3 "Numbers Racket: Why the Economy Is Worse Than We Know."

${ }^{4}$ See, for example, the June 2008 Investment Outlook by Bill Gross of PIMCO, entitled, "Hmmmmm?" as well as the July 7, 2008 Bloomberg article, “TIPS Flunk Inflation Test as Fuel, Food Overtake CPI," by Sandra Hernandez."

${ }^{5}$ This paper does not add to the literature on the cost/benefit analysis of the TIPS program from the perspective of the Treasury. For such analyses, please see, among others, recent papers by Sack and Elsasser (2004), Roush (2008), and Roush, Dudley, and Steinberg Ezer (2008).
} 
expectations as implied by break-even inflation rates and survey measures of consumers' inflation expectations is also addressed.

We find that for a buy-and-hold investor, the most frequently criticized adjustments made to the measurement of the CPI render an inflation basis risk that is not correlated with any of the more common systematic risk factors, such as the excess return on the stock market. In addition, inflation basis risk resulting from the use of the CPI, as opposed to otherincluding more tailored-inflation measures, is also uncorrelated with any of the systematic risk factors. As a result, investors need not be compensated for such basis risk arising from these CPI measurement factors or from using the CPI instead of a more tailored inflation measure, such as one for the elderly. By this standard, securities linked to the CPI provide a good real-return hedge, in spite of measurement error in the CPI, and in spite of possible demographic differences across investors. We also show that a long-term, buy-and-hold investor is better protected from future unexpected changes in inflation than an investor who holds the securities for a short term and for less than the full maturity. In addition, we explain why break-even inflation rates implied from the simultaneous consideration of the nominal Treasury and TIPS markets are neither clean measures of expected future inflation nor necessarily good predictors of future inflation. Finally, we conclude that while, in principle, one can think of alternative Treasury instruments linked to different inflation measures that are more tailored to particular demographics, indexing TIPS to the CPI-U (the CPI for urban consumers) seems best from a cost/benefit perspective.

The paper is organized as follows. Section II describes TIPS in more detail, emphasizing how they are designed to act as protection against changes in inflation, the tax implications for investors, the demographics of holders of TIPS, and other considerations relating to whether or not TIPS should yield measures of break-even inflation rates comparable with survey measures of consumers' inflation expectations or future realized rates of inflation. Section III outlines and evaluates the criticisms of the CPI and speaks to whether its potential mismeasurement is relevant to the efficacy of TIPS as a hedging instrument to guarantee the real return. It also discusses whether the CPI is a good measure for everyone, and whether there might be more appropriate measures for certain heterogeneous groups, along with the costs and benefits of 
issuing such securities. Section IV demonstrates the efficacy of TIPS as a hedge against various ex ante and ex post inflation measures, as well as the efficacy of TIPS as a short-term versus a long-term hedge. The final section concludes with implications for the design of the TIPS market.

\section{The market for TIPS - how they work, who uses them, and how they are used}

Indexed bonds in general, and TIPS in particular, are designed to provide a certain pre-tax real return. With TIPS, this is achieved by adjusting the principal for inflation, that is, multiplying the principal by an index ratio for accrued CPI inflation from the date of first issuance of that security. ${ }^{6}$ For a particular date, this quantity is essentially the ratio of the three-month lagged CPI value at this date divided by the CPI value at the time of the first issuance of the security in question. The semi-annual interest payment on TIPS is then calculated as this adjusted principal amount multiplied by (one half of) the fixed rate of interest determined at auction. In the case of the principal repayment, The Treasury also guarantees that the redemption of principal will not be below the amount of principal originally invested, so that principal is protected from declines in the CPI since the issuance date. ${ }^{7}$ TIPS and nominal Treasuries are treated alike for tax purposes, in that the compensation for inflation is taxed as interest income in both cases. Hence, the ex ante nominal tax burden is certain for nominal Treasuries but uncertain for TIPS, whose pre-tax nominal return is uncertain. However, the ex ante real tax burden is uncertain for both TIPS and nominal Treasuries, although likely to a lesser degree for TIPS. ${ }^{8}$

Unfortunately, to our knowledge there is no demographic information available about the end consumers of TIPS, as no such information is available from the secondary market, and the information provided by the U.S. Department of the Treasury regarding competitive auction

\footnotetext{
${ }^{6}$ The reference price level index is the CPI-U, NSA. Please see Kan (1999).

${ }^{7}$ For more detailed technical information, please see Department of the (U.S.) Treasury (1997), "Sale and Issue of Marketable Book-Entry Treasury Bills, Notes and Bonds," (Circular, Public Debt Series No. 1-93, January), or the accessible and more succinct exposition by Deacon, Derry, and Mirfendereski (2004).

${ }^{8}$ For a more thorough discussion of this point please see "Inflation-Indexed Bonds: The Dog That Didn't Bark" by Richard W. Kopcke and Ralph C. Kimball, New England Economic Review, January/February 1999.
} 
winners is aggregated. A number of studies are suggestive, though, regarding who TIPS holders are likely to be (see, among others, Hammond (1999), Anderson (1999), Kinney (1999) and Shelton (2000)). These studies contend, for example, that TIPS are better suited to buy-andhold investors than to frequent traders. They suggest TIPS for investors who have retirement income not indexed to inflation. They further reason that investors such as pension funds - or indeed any investor - who may need to match assets against liabilities in real terms are natural holders of TIPS.

The aggregate data available are somewhat supportive of such studies' claims regarding the demographics of likely TIPS owners. From various Treasury publications, it is clear that when compared with their nominal counterparts, the distribution of competitive auction awards for TIPS has a smaller share of awards allocated to primary dealers and a much higher share allocated to "investment funds" and "other." Here, "primary dealers" are government dealers (banks or broker-dealers) who may trade government securities directly with the Federal Reserve Bank of New York and who report to the Government Securities Dealers Statistics Unit of that bank; "investment funds" are defined to include investment managers, mutual funds, and hedge funds; while "other" includes individuals, non-financial companies, and financial companies other than dealers, depository institutions, and insurance companies. ${ }^{9}$ Figure 1 gives the most recent Department of Treasury distribution of competitive awards for 10-year TIPS and 10-year nominal Notes. ${ }^{10}$ From this figure it is clear that for auctions occurring between 2003: Q3 and 2004: Q2, the share of competitive awards awarded to primary dealers was 54 percent for TIPS and 64 percent for the nominal equivalents. The share of awards granted to the "other" category was 8 percent for TIPS compared with 3 percent for nominal Treasuries, and the share of TIPS competitive auction awards awarded to "investment funds" was 31 percent compared with just 10 percent for nominal Treasuries. Previous pie charts provided by the Department of the Treasury yield similar implications.

\footnotetext{
${ }^{9}$ For a list of the primary government dealers, please see: http://www.newyorkfed.org/markets/pridealers current.html .

${ }^{10}$ A series of these figures can be found here: http://www.treas.gov/offices/domestic-finance/debt-management/qrc/ though the most recent figure found and reproduced in this paper is from a June 2004 PowerPoint discussion by Timothy Bitsberger, the then Deputy Assistant Treasury Secretary for Financial Markets, which can be found by following the link “Treasury Debt Management" available at: http://www.ustreas.gov/press/releases/js1726.htm.
} 
In addition to providing a certain pre-tax inflation-adjusted return, TIPS are also useful for constructing financial market-based measures of "inflation compensation," or what is more commonly referred to as "break-even inflation rates." While there are a number of practical approaches for backing out the implied break-even inflation rates by simultaneously considering nominal Treasuries and TIPS, one can think of the implied break-even inflation rate as the nominal Treasury yield less the equivalent TIPS yield. ${ }^{11}$ Figure 2 abstracts from differential liquidity, tax, and convexity conditions in these two markets and shows simply how the nominal Treasury yield can be broken down into a TIPS part-the expected real rate plus a real rate risk premium-and the inflation compensation part, consisting of both expected inflation and the inflation risk premium. This diagram demonstrates one reason why these measures of inflation compensation or break-even inflation rates are not pure measures of "inflation expectations," despite the fact that some commentators use these terms interchangeably, since inflation compensation also includes an inflation risk premium.

Differential liquidity premia in nominal Treasury securities and TIPS, differences in their relative convexity, and differential ex ante uncertainty regarding tax payments are also, like the inflation risk premium, embedded in the break-even inflation rate. So, for these reasons, too, the break-even inflation rate is not a pure measure of "inflation expectations." $12,13,14$ Thus,

\footnotetext{
${ }^{11}$ Investors participating in both nominal Treasury and TIPS markets ensure that arbitrage opportunities across these two markets are traded away. This implies that we can assume that the expected real rate and the real rate risk premium in the two markets is the same, and we can use this information to back out the expected break-even inflation rate from these two markets. In the absence of differential liquidity or convexity premia, the break-even inflation rate is the rate of inflation compensation (expected inflation plus the inflation risk premium) consistent with no arbitrage between these markets.

${ }^{12}$ A paper by D'Amico, Kim, and Wei (2008) illustrates how this liquidity premium in TIPS has dropped over time for the 5- and 10-year TIPS yields. Before 2003, their estimated liquidity premium was around 100 basis points for these maturities. Thereafter, it was estimated to be closer to zero. Of course, with the financial turmoil since August of 2007, the resultant flight to quality to nominal Treasuries, and the reported drying up of liquidity in the TIPS market, this liquidity premium would have become large and positive again. Nonetheless, the authors do argue that break-even inflation rates implied by TIPS are reasonable proxies for inflation expectations. The Office of Debt Management's August 2005 publication entitled "The Inflation Protected (TIPS) Market" demonstrates a similar phenomenon by calculating turnover rates-the ratio of total value traded to market capitalization-in nominal Treasuries and TIPS.

${ }^{13}$ A convexity bias can arise from the fact that interest rate compounding implies that bond prices will respond asymmetrically to changes in yield-they are more sensitive to a fall in yield than to an increase in yield; consequently, the bond prices will rise with the volatility of yield, and this will push down the forward rates below the expected future rates. The convexity adjustments are likely to differ across the nominal Treasury and TIPS forward curves. Please see the speech by Mr. Christian Noyer, the Governor of the Bank of France, in the BIS Review
} 
even if we had a clean survey measure of consumers' inflation expectations, we could not expect the break-even rate to be even close to perfectly correlated with such a measure. Of course, such a comparison is further complicated by the fact that the participants whose expectations are reflected in these measures may be different in the survey sample and in the financial market sample. Too, it is not always clear what the expectations are measuring, for example, it probably is not CPI-U NSA for every participant in the survey sample. For these various reasons, we also cannot expect the break-even inflation rate-without adjustments for these different risk premia - to be a good forecast of future inflation.

\section{The CPI, alternative inflation measures, and hedging}

The CPI, and particularly the application of various index number methods for its construction, came under renewed and sometimes harsh criticism in 2008, especially during the months when oil prices spiked. In this section, we briefly discuss the three aspects of the CPI methodology that are most subject to popular criticism: treatment of substitution bias, quality adjustments, and owners' equivalent rent.

Our focus is on the methodological choices of the Bureau of Labor Statistics (BLS) concerning these three aspects of price index construction and the implications of these choices for the purpose of hedging real returns due to inflation risk - specifically for investors who hold TIPS to maturity and consume the coupon payment every period. That is, in this section, we ignore the random capital gain (loss) if TIPS are sold prior to maturity. ${ }^{15}$ We show that, whatever bias there may be in the CPI as an inflation measure, the optimal strategy for hedging against unexpected inflation fluctuations is unaltered, as long as the bias is time-invariant. Rather, investors care about the time variations in the bias, which constitutes a basis risk for

37/2004; Deacon, Derry and Mirfendereski (2004); and Anderson, Breeden, Deacon, Derry, and Murphy (1996) Estimating and Interpreting the Yield Curve, Chapter 8, Chichester: John Wiley \& Sons.

14 There are also duration differences between nominal Treasuries and TIPS, as TIPS are relatively more back-loaded than their nominal counterparts as a result of the inflation uplift in the principal over time.

${ }^{15}$ As shown above, TIPS are risk free (in terms of real rate of return) only if held till maturity. Since the real rate is stochastic, TIPS are still subject to random capital gains (losses) if sold prematurely. 
investors who want to hedge the real rate of return. ${ }^{16}$ To the extent that this bias is correlated with the risk factors priced in the market, investors would demand a risk premium for bearing that risk; some would prefer to hedge that risk, given its prevailing market price. Either way, if this bias is perceived to be present and priced in the Treasury markets, then it is likely embedded in the inflation risk premium implied by the simultaneous consideration of nominal and real Treasury yields. ${ }^{17}$

We then consider the likely "basis risk" in using the CPI to hedge inflation risk. The further away a household's expenditure weights are from the average, the greater this basis risk, since the CPI measures the price change of the average consumption bundle. Again, this would be priced and captured in the inflation risk premium. We then explore some alternative aggregate price indexes.

\section{III.A Index methodology and popular criticisms of the CPI}

We first briefly review the index number methodology underlying the consumer price index (CPI). The CPI is generally a short-hand for CPI-U, a price index that covers the out-of-pocket expenses of all urban consumers. It is compiled by the Bureau of Labor Statistics (BLS). The detailed item-area level prices (such as the price of apples in Chicago) are based on surveys conducted at retail outlets, while the expenditure weights used to aggregate the individual price series are based on data from the Consumer Expenditure Survey. The CPI uses the expenditure shares averaged across all (urban) consumers. By construction, the CPI is a modified Laspeyres index. A simplified version of the index formula can be illustrated using the (gross) inflation rate between periods $t-1$ and $t: 18$

\footnotetext{
${ }^{16}$ It is worth pointing out that hitherto few studies of CPI bias have made this point explicitly. Most such studies are concerned with the average level of the biases. For recent examples, see Lebow and Rudd (2003) and Gordon (2006) for in-depth discussions of the likely biases in the CPI and estimates of the average level.

${ }_{17}$ Note that, to the extent that the marginal investor in the TIPS market does not buy and hold, the systematic risk in the random capital gain (loss) from trading TIPS prior to maturity should be priced as well. It is probably also embedded in the implied inflation risk premium. Here we ignore this issue.

${ }_{18}$ For the exact formula, in particular the change since 1999, when the BLS introduced use of the geometric mean within some item-area strata, see the CPI manual (Chapter 17 of the BLS Handbook of Methods).
} 


$$
\Pi_{t-1, t}=\sum_{i=1}^{N} p_{t}^{i} q_{t 0}^{i} / \sum_{i=1}^{N} p_{t-1}^{i} q_{t 0}^{i}
$$

$N$ is the number of products, $t_{0}$ is the base-period for period $t$, and $p^{i}$ and $q^{i}$ are the price and quantity (serving as aggregation weight) for product $i$, respectively. Currently, the base year is updated every three years. The formula makes clear that, as with any Laspeyres index, the constituent individual price changes in the CPI are weighted by their share in the consumption bundle in the base period.

In 1997, the BLS embraced the Boskin Commission's recommendation that the CPI be constructed as a cost of living index. As such, it is intended to gauge how much the average consumer's income would need to change between two time periods in order to keep pace with the overall cost of goods and services to enable the consumer to maintain the same standard of living in terms of satisfaction level (utility). So the key here is that the consumer would be left no better or worse off, not that the consumer would necessarily be able to purchase the same basket of goods and services.

The methods adopted by the BLS to make the CPI a more accurate index for the cost of living have come under popular criticism from a number of perspectives. Among these, three criticisms, each corresponding to a methodological choice, are potentially most relevant for hedging purposes. The first criticism concerns the way the CPI deals with likely upward biases in deflators due to the substitution effect. The second argues against the use of hedonic models to adjust for product quality changes, or even the whole concept of quality adjustment. The third touches upon the subindex for the cost of housing. In the popular press, these adjustments are cited as contributing to understating CPI inflation, while the experts in price index methodology still contend there is an upward bias in measured CPI inflation, even after these adjustments are made. We consider, in turn, the three primary criticisms leveled against the methodological choices made by the BLS in their construction of CPI-like indexes. ${ }^{19}$

\footnotetext{
${ }^{19}$ Greenlees and McClelland (2008) of the BLS published a timely article aiming to address the criticisms and complaints most popularly circulated in the public domain about what they term the "myths" regarding the CPI. In addition to these three criticisms, they also consider core vs. headline CPI.
} 


\subsubsection{Substitution bias and chain weighting}

According to index number theory, one of the major drawbacks of a Laspeyres price index is that it does not account for the substitution effect and thus tends to overstate the true rate of price change. That is, as long as products are substitutable to some extent, consumers most likely will buy a different consumption bundle when the relative prices change. Specifically, consumers generally choose to substitute away from goods and services whose relative prices have risen and toward those whose relative prices have fallen. This is especially relevant at highly disaggregated levels of product categories, such as breakfast cereals and carbonated soft drinks, where the cross-product elasticity of substitution is high. What this means is that consumers can achieve the same level of utility without needing income to rise by the same percentage as the (weighted) price increase on the old consumption basket.

Index number theory suggests that the substitution bias is best mitigated by a "superlative" index, such as the chain-weighted PCE deflator. ${ }^{20} \mathrm{~A}$ key feature of superlative price indexes is that the aggregation weights are updated in a timely manner to reflect changes in expenditure shares in the average consumption basket. The CPI has improved along this dimension: even though it remains a Laspeyres index (that is, an index that uses only the expenditure weights in the base year) at the "upper-level" of product categories (that is, across the so-called area-item strata), it now updates the base year with a lag of only three years, instead of an average of 11 years prior to 2002 (U.S. BLS 1999). ${ }^{21}$ Nevertheless, studies put the magnitude of the remaining "upper-level" positive bias due to the Laspeyres formula at $0.1-0.4$ percentage points per year. ${ }^{22}$

In addition, starting in January 1999, the BLS adopted the geometric mean formula for index categories that make up about 61 percent of total spending in the CPI. ${ }^{23}$ This amounts to

\footnotetext{
${ }^{20}$ See Diewert (1998) for a summary in the context of the CPI, including comparisons with a true superlative index.

${ }^{21}$ In total, there are roughly 8000 such item-area strata in the CPI.

${ }^{22}$ See Lebow and Rudd (2003) and Gordon (2006).

${ }^{23}$ More specifically, the geometric mean calculation is only performed across merchandise within each item-area stratum. It is applied in order to mitigate the within-stratum substitution bias (the so-called "lower-level" bias). By contrast, the CPI's Laspeyres formula across the item-area strata amounts to assuming no substitutions across strata, for example, oranges vs. apples in Chicago.
} 
assuming unitary (instead of zero) elasticity of substitution across those products. This change is estimated to have reduced the upward bias of measured CPI inflation by about 0.2 percentage points. ${ }^{24}$

\subsubsection{Quality adjustments, new products, and hedonic models}

The other major complaint against the methodology of official price indexes concerns quality adjustment-imputing and removing the portion of the change in a good's price that is due to quality variations. That is, only price increases that are not due to advances in a good's quality - broadly defined to encompass a wide array of attributes (from simple tangible ones, such as the weight of a bottled water to less visible ones. such as the clock speed of a CPU chip) - count as true price movements. The logic of this adjustment is straightforward: at the fundamental level, consumers derive utility from the desirable characteristics of each good or service, and changes in the number and level or such characteristics thus should alter the utility consumers derive from the good.

The specific class of approaches to quality adjustment that has encountered the most voluble criticism is the class encompassing so-called hedonic models. These models are essentially a multivariate regression technique that isolates the value of a marginal change in a particular product characteristic. One major application of hedonic models is to isolate the true price change when old models of products are replaced by new models or when entirely new varieties of products appear on the market. The hedonic method is needed because the price of a new model or new good needs to be compared with a reference product (for example, the old model) that does not exist and whose hypothetical price thus has to be inferred through regression analysis.

For our purpose, we focus on the quantitative impact of quality adjustments, in particular those done with hedonic models. ${ }^{25}$ The total CPI expenditure weight of products subject to hedonic adjustment is about 32 percent, of which 31 percentage points are accounted for by

\footnotetext{
${ }^{24}$ Greenlees (2006) confirms this initial estimate of the likely reduction in bias.

${ }^{25}$ See Greenlees and McClelland (2008) for more detailed discussions of the general concept of quality adjustment and the specific properties of hedonic models.
} 
shelter and apparel (an adjustment in place for over two decades), and the remainder by consumer durables (an adjustment introduced in 1998), such as personal computers, microwave ovens, and televisions. Ironically, criticisms of this adjustment notwithstanding, hedonic quality adjustment of housing units due to aging adds about 0.2 to 0.3 percentage points per year to the inflation of shelter price. ${ }^{26}$ Hedonic adjustments applied to consumer durables have had minimal impact on inflation-increasing the rate by 0.005 percent per year. ${ }^{27}$

\subsubsection{Owner's equivalent rent, shelter cost, and house prices}

Criticism has also been directed at the way the CPI accounts for the price change of housing services, especially the component called the owner's equivalent rent (OER) for primary residence. There was especially widespread disapproval during the height of house-price appreciation in 2003-2005, as the OER decelerated, in fact growing at its slowest pace since the mid-1980s (Figure 3).28

This significant divergence in recent boom years between OER inflation and house-price appreciation is, however, unusual by historical standards. Between 1982 and 2002 (the OER series extends back only to 1982), the OER and the FHFA house-price index were reasonably correlated in terms of growth rate $(\rho=0.29) .{ }^{29}$ After 2003, the correlation between the two inflation rates fell to -0.18 . So it seems that both the OER component of the CPI and a hypothetical security indexed to the OER would be poor hedges for house prices, primarily during periods of house-price bubbles.

\footnotetext{
${ }^{26}$ See Poole, Ptacek, and Verbrugge (2005) for more details. Brown and Stockburger (2006) estimate that the hedonic method has slightly increased the inflation rate for apparel prices as well.

${ }^{27}$ See Johnson, Reed, and Stewart (2006).

28 The house-price index is the repeat sales index compiled by the Federal Housing Financing Authority (FHFA). We use the longer time series of the composite index (which includes actual sales as well as refinancing transactions), but none of the qualitative results would be affected if we used the sales only index. Growth rates of the two indexes are highly correlated and had similar mean values until 2004, after which the sales only index generally had a lower growth rate than the composite index.

${ }^{29}$ If we include the previous house-price boom in 1976 to 1979 by extending the sample to 1976 (when the FHFA index began), and approximate the OER using the rental cost of primary residence, then the correlation rises to 0.52 (between 1976 and 2002). The primary rent series is a reasonable proxy for the OER, since the correlation between their inflation rates runs steadily at 0.79 during the overlapping years (since 1982).
} 
At a fundamental level, the discrepancy, or even extended divergence, in growth rates between house prices and the OER lies in the fact that the former concerns the investment aspect, whereas the latter concerns the consumption aspect of housing. Unlike most other products in the CPI basket, real estate is also the primary vehicle for wealth accumulation for most households. This means that the price of a house is analogous to the price of a stock; both are equal to the present discounted value of the income stream generated by a long-lived asset. In contrast, the OER is an application of the rental equivalence approach to capturing the opportunity cost of the current-period services generated by the (physical) housing capital and consumed by households. ${ }^{30}$ As such, it follows the same principle as shelter cost for renters.

This conceptual distinction between house prices and the OER suggests that it would be desirable to make available separate financial instruments to enable households to hedge the risk of house-price fluctuations. We discuss this in greater detail in the next subsection. Here, we focus on the OER as a measure of homeowners' per-period cost of consuming shelter services. A major practical shortcoming of the OER is that the housing units in the CPI sample may not be representative of the average owner-occupied dwelling. To the extent that the rental price dynamics for these units differ from those for typical owner-occupied residences, indexing to the CPI could provide a poor hedge for owner occupiers. Moreover, for the rental income homeowners hypothetically forego to be the valid opportunity cost of the housing services, homeowners would need to be able to switch costlessly between owning and renting their houses. This is clearly an unrealistic assumption. In particular, high transaction costs in the real estate market render such transitions unprofitable even at an annual frequency (Verbrugge, 2008). The resulting wedge between homeowners' true shadow rental price and the OER becomes another basis risk for hedging shelter cost risk.

\footnotetext{
${ }^{30}$ In theory, the user cost of (housing) capital should give the same measure of per-period price of housing services as the rental equivalence approach behind the calculation of OER. The user cost (also called the rental price) of capital depends not only on the price of the capital good (that is, the house price here) but also on the depreciation rate and the financial cost of capital, which in turn depends on the mortgage interest rate, and on property and income tax rates. In reality, however, the OER and the user cost are found to diverge for extended periods (Verbrugge 2008), mainly as a result of substantial transaction costs in the real estate market.
} 


\section{B Systematic risk of the CPI bias and implications for hedging}

Quite a few studies have estimated the impact of the methodological changes in the CPI following the Boskin commission's report, as well as the remaining substitution bias-positive on average -in the CPI. However, all of these estimates concern the average magnitude of bias over particular sample periods, in large part because of data limitations-any estimate of the bias in a particular month or quarter is surrounded by a high degree of uncertainty. For this reason, we urge the reader to interpret with caution the numerical estimates of likely time variations in the CPI biases presented here.

For TIPS investors whose purpose is to obtain a certain real rate of return, that is, to hedge the risk of unexpected fluctuations in the true inflation rate, the presence of biases in the CPI does not per se pose a problem. If the CPI always overstates true inflation by $\mathrm{x}$ percent, then investors should just reduce the amount invested in TIPS by x percent, and vice versa. Only when the bias in the CPI is time varying does it constitute a basis risk. The more variable the cumulative bias in the CPI over a holding period, the more imperfect a hedge against true inflation offered by TIPS. ${ }^{31}$

Moreover, if this basis risk covaries with priced risk factors, investors would demand a return premium on TIPS. Express the overall CPI bias as $\pi-\pi^{*}$, where $\pi$ and $\pi^{*}$ denote the official and the true inflation rate, respectively. For the hedging investors, $\pi-\pi^{*}$ is also the unexpected portion of the real rate of return on TIPS..$^{32}$ So, it satisfies the following standard asset pricing equation:

$$
\mathrm{E}_{t}\left\{M_{t+1}\left[1+\left(\pi_{t+1}-\pi_{t+1}^{*}\right)\right]\right\}=1 .
$$

$M_{t+1}$ is the relevant stochastic discount factor (more on this later), which can be expressed in terms of the ratio between current and future marginal utilities in a representative consumerinvestor framework.

\footnotetext{
${ }^{31}$ One implication is that if the CPI bias is independently and identically distributed, then the longer the holding period, the less the bias matters for hedging purposes as time averaging smoothes out the variations.

${ }^{32}$ This is precise under continuous compounding. In discrete time, the expression for the unexpected return should be $(1+r)\left(\pi-\pi^{*}\right) /\left(1+\pi^{*}\right)$, where $r$ is the real interest rate set at auction.
} 
Equation (2) implies that the covariance between the basis risk and the market risk factors determines the risk premium on TIPS demanded by investors who want to hedge the risk of the true inflation process. Following the asset pricing literature, we approximate the market risk factors, using the return on the value-weighted market index as well as two additional factors that capture the return premium on small firms and value stocks (that is, low market-to-bookvalue multiples; see Fama and French, 1993 and 1996 for details). We note, however, that these variables may not precisely capture the risk factors relevant for TIPS investors if the wealth portfolio or the consumption path of the representative TIPS investor differs systematically from that of the representative stock market investor.

For instance, note that equation (2) makes clear that this basis risk does not arise for (institutional) investors who use TIPS to maturity-match their real liabilities that are indexed to the official, not the true, underlying inflation, since in this case $\pi^{*}=\pi$. An example of such institutions would be pension funds with liabilities indexed to the CPI-U. This suggests the possibility that the premium priced in the TIPS market may be smaller than would be implied by the covariance between the remaining CPI bias and the market factors if some participants are those institutional investors who seek to hedge the inflation risk as officially measured.

To gauge the substitution bias that may still be present in the CPI, our preferred proxy is the gap between the regular CPI and the chained CPI (or C-CPI-U). The latter is constructed using the same underlying micro price data as the regular CPI, but using chain weighting (at the upper-level) to further reduce substitution bias. ${ }^{33}$ The BLS started publishing the C-CPI-U in 2002, with data going back to December 1999. Figure 4 shows that, as would be expected, the inflation rate as measured by the chained CPI tends to be lower than the rate as measured by the CPI; that is, the substitution bias is on average positive -0.38 percentage point per annum, to be precise. ${ }^{34}$ Since the time series of the C-CPI-U is rather short, we also use the difference between the CPI-U and the PCE deflator to approximate the basis risk over a longer sample

\footnotetext{
${ }^{33}$ Part of the gap is bias due to the slow incorporation of new products into the regular CPI, which uses expenditure weights updated every three years, whereas the chained CPI also uses current period expenditure shares, which incorporate new goods more quickly.

34 The C-CPI-U is only available non-seasonally adjusted, because the BLS deems data for the C-CPI insufficient to conduct seasonal adjustment. So the non-seasonally adjusted CPI is used for consistency. To minimize the influence of seasonality, the inflation rates are computed as the four-quarter growth rate.
} 
period. Like the chained CPI, the PCE deflator is constructed using a similar methodology that substantially mitigates the substitution bias. But using the PCE deflator also introduces noise, because it differs from the CPI-U along a few other dimensions such as scope (see Section 3.3.1 for more details). Nevertheless, this latter proxy can still produce an unbiased, albeit less precise, estimate of the systematic risk in the remaining substitution bias, to the extent that the differences between the CPI-U and the PCE deflator in terms of scope, etc., are uncorrelated with the market risk factors. Empirically, across the overlapping sample period for these two series, these two proxies are reasonably correlated ( $\rho=0.25$ with a p-value of 0.009$)$.

Table 1 presents the factor loadings of the possible basis risk due to the CPI substitution bias. They are estimated using non-overlapping monthly data, which amounts to assuming that investors could somehow receive inflation compensation on a monthly basis. Our preferred proxy of the residual substitution bias is basically uncorrelated with the overall stock market return, according to either the simple market model or the augmented model that includes the two Fama-French factors. ${ }^{35}$ The longer time series of the proxy based on the inflation difference between the CPI-U and the PCE deflator shows statistically significant loading on the market return as the single risk factor. But the loading is economically small. ${ }^{36}$ When the two FamaFrench factors are added, the loading becomes insignificant on any of the three factors. So it seems that, for hedging purposes, the official CPI index is adequate, since the bias possibly still present contains little systematic risk.

Without time series data of the bias due to insufficient quality adjustments in the CPI, especially bias concerning quality adjustments for new products, we are unable to estimate the covariance of the CPI with the three aggregate risk factors. So, here we merely discuss its cyclicality as a proxy. Broda (2004) offers a preliminary estimate indicating that this bias may

\footnotetext{
${ }^{35}$ Since the only available C-CPI-U index is non-seasonally adjusted, to be consistent, we compute the difference in inflation using the NSA CPI-U series. We then include a full set of month dummies in the regressions to remove seasonal variations in this proxy for the residual CPI bias. Four out of 11 of the month dummies are significant, and they collectively explain about 15 percent of the variation. Note, too, that TIPS are actually indexed to the NSA version of the CPI-U, another reason for studying these series.

${ }^{36}$ In this regression, both the CPI-U and the PCE deflator are seasonally adjusted, and, as would be expected, the month dummies are insignificant.
} 
be procyclical. ${ }^{37}$ Data since 1990 show that the bias was greater in the late 1990s, a time of above-average economic growth. The likely reason for this procyclicality is that more new products are introduced during boom times than during downturns, so the CPI's deficiency in quality adjustments becomes more acute in booms.

Likewise, it is also difficult to gauge the systematic risk of the bias due to practical shortcomings of the OER, because of the lack of necessary micro data. So, here we only discuss some qualitative conjectures, primarily in terms of the cyclicality of this bias. First, to impute (changes in) the implicit rent homeowners would have to pay each month, the CPI adjusts the actual rent paid by renters in the same sampling area-mainly by removing the utilities cost, which is often included in rent and considered a subsidy. This means that the OER inflation would likely be artificially low in periods with rapid increases in energy cost, since rent is generally rather sluggish. This tendency can be seen clearly in recent years (Figure 5), as oil prices rose substantially. But this distortion is little correlated with the market return, so TIPS investors may not need compensation for bearing this basis risk. Second, areas with high homeownership rates have been increasingly under-represented in the rental price sample (Poole, Ptacek, and Verbrugge, 2006). To the extent that the dynamics of rent differ across areas and are correlated with the homeownership rate, there may have been low-frequency variations in the bias in the OER. But there is little reason a priori to expect a significant systematic component in such changes over time.

In summary, there is little to suggest that the bias in the CPI due to each of the three arguably most prominent aspects of methodological choice is correlated with the typical aggregate risk factors. Taken together, the overall influence of these methodological choices for the CPI bias is also unlikely to co-move significantly with aggregate risk factors. To the extent that the three biases discussed above dominate fluctuations in the biases in the CPI components, biases that may still be present in the CPI should matter little to investors who use TIPS to hedge return risk due to the true inflation process. We emphasize again that investors care

\footnotetext{
${ }^{37}$ This is the only study we are aware of that estimates cyclical variations in the CPI's biases. In fact, its time series of the CPI bias is a composite of biases due to both substitution and the introduction of new products. But according to Broda (2004), in terms of size, on average two-thirds of the bias is related to new products.
} 
about fluctuations in the bias in the CPI, but not the bias per se, since it is the fluctuations that introduce basis risk and prevent investors from perfectly hedging the true inflation risk.

\section{III.C Best price index or indices for inflation protection}

\subsubsection{The CPI, heterogeneous consumption bundles, and the basis risk}

The CPI is an index number designed to measure the "average" price level experienced by the relevant population. That is, the weights used for aggregating price changes in the thousands of items covered by the CPI-U are the expenditure shares averaged across all urban consumers. ${ }^{38}$ So, by design, the CPI does not correspond to the exact price changes experienced by any individual consumer, unless she consumes exactly the average basket of goods and services in every period. ${ }^{39}$

The existence of such deviations does not by itself render TIPS an imperfect instrument for hedging against inflation risk. Just as in the above case of biases in the CPI, if the inflation rate on an individual's consumption bundle is constantly $\mathrm{x}$ percent higher (lower) than the CPI inflation, then the consumer should simply invest $x$ percent more (less) in TIPS. This is, however, unlikely to be a realistic case. Instead, the idiosyncratic inflation rate experienced by an individual consumer almost surely deviates from the average (that is, the CPI) inflation rate in a time-varying manner. If this deviation is correlated with the stochastic discount factor relevant for that consumer, then, again, a basis risk arises when she uses TIPS to hedge against inflation risk.

The logic can be illustrated using exactly the same equation as (2), once we interpret $\pi$ and $\pi^{*}$ as the CPI and the consumer-specific inflation, respectively. To help gain intuition about the return implication of this basis risk, we look at a commonly used model-the consumption capital asset pricing model (CAPM) - where the stochastic discount factor $\left(M_{t+1}\right.$ in equation (2))

\footnotetext{
38 Specifically, the expenditure shares are calculated based on data from the Consumer Expenditure Survey conducted by the Census Bureau on behalf of the BLS.

${ }^{39}$ Note that this is independent of the substitution bias in the CPI, which would cause the CPI to mis-measure the true price change even if a representative consumer existed.
} 
equals the marginal utility ratio. Further assume that there are idiosyncratic taste shocks so that each consumer i's discount factor equals her marginal utility ratio $u^{\prime}\left(C_{t+1}^{i}\right) / u^{\prime}\left(C_{t}^{i}\right)$; then equation (2) can be expressed as:

$$
\mathrm{E}_{t}\left[\left(1+\pi_{t+1}-\pi_{t+1}^{*}\right) u^{\prime}\left(C_{t+1}^{i}\right) / u^{\prime}\left(C_{t}^{i}\right)\right]=1 .
$$

This means that if consumer $i$ tends to consume more goods that experience relatively faster price increases (that is, a negative $\pi-\pi^{*}$ ) while she raises her consumption and vice versa, then, other things being equal, she will be willing to accept a lower rate of return (that is, a negative premium) on TIPS. In other words, if, as her consumption grows, her consumption bundle becomes relatively more expensive than the average consumption bundle, she will value the real-return hedge provided by TIPS more than the consumer consuming the average consumption bundle and therefore require a lower rate of return than that representative consumer. Note that since the idiosyncratic risk $\pi-\pi^{*}$ is non-diversifiable, it is relevant even if the discount factor is the same across all consumers.

In fact, a basis risk arises whenever the price index used for the inflation-protected security deviates from a consumer's specific price index, and the resulting deviation in the inflation rate is correlated with her stochastic discount factor. This generally means that, as long as there is cross-sectional heterogeneity in period-to-period changes in consumption bundles, individuals are exposed to a basis risk if the inflation-protected bonds available are all indexed to aggregate price indexes, regardless of the exact indexes used. For any specific price index, such as the CPI, the cross-sectional range of this basis risk could be estimated based on a sample distribution of expenditure shares using survey data of expenditures at the individual household level.

\subsubsection{Costs and benefits of price indexes for sub-populations}

The type of basis risk arising from such heterogeneous consumption bundles as described in equation (3) is a form of market incompleteness. If there were no transaction costs (broadly defined), it would be ideal for the government to issue a separate bond, indexed to the price of a consumer's particular consumption bundle, so that she would be perfectly hedged. With the 
basis risk eliminated, the consumer would no longer demand the associated risk premium and thus would be willing to accept, other things being equal, a lower real rate of return on the tailor-made inflation-protected bond. The government thus could offer a lower average real yield on these bonds in the aggregate. At the same time, it would be paying the same amount of inflation compensation, since the average of individual inflation rates equals the inflation rate of the average consumption basket. This can be shown by expanding and rearranging the terms in equation:

$$
\begin{aligned}
& \Pi_{t-1, t}=\sum_{i=1}^{N}\left(\frac{p_{t 0}^{i} q_{t 0}^{i}}{\sum_{i=1}^{N} p_{t 0}^{i} q_{t 0}^{i}}\right) \pi_{t-1, t}^{i}=\frac{\sum_{i=1}^{N}\left(p_{t 0}^{i} \sum_{j=1}^{M} q_{t 0}^{i j}\right) \pi_{t-1, t}^{i}}{\sum_{j=1}^{M} \sum_{i=1}^{N} p_{t 0}^{i} q_{t 0}^{i j}} \\
& =\frac{\sum_{j=1}^{M}\left[\left(\sum_{i=1}^{N} p_{t 0}^{i} q_{t 0}^{i j} \pi_{t-1, t}^{i}\right) / \sum_{i=1}^{N} p_{t 0}^{i} q_{t 0}^{i j}\right] \sum_{i=1}^{N} p_{t 0}^{i} q_{t 0}^{i j}}{\sum_{j=1}^{M} \sum_{i=1}^{N} p_{t 0}^{i} q_{t 0}^{i j}}=\sum_{j=1}^{M}\left(\frac{\sum_{i=1}^{N} p_{t 0}^{i} q_{t 0}^{i j}}{\sum_{j=1}^{M} \sum_{i=1}^{N} p_{t 0}^{i} q_{t 0}^{i j}}\right) \Pi_{t-1, t}^{j}
\end{aligned}
$$

where $i$ indexes goods, while $j$ indexes individuals, so $q_{t 0}^{i}=\sum_{j=1}^{M} q_{t 0}^{i j} \cdot \pi_{t-1, t}^{i}=p_{t}^{i} / p_{t-1}^{i}$, while $\Pi_{t-1, t}^{j}=\left(\sum_{i=1}^{N} p_{t 0}^{i} q_{t 0}^{i j} \pi_{t-1, t}^{i}\right) / \sum_{i=1}^{N} p_{t 0}^{i} q_{t 0}^{i j}$ denotes the (gross) inflation rate between periods $t-1$ and $t$, based on consumer $j$ 's price index. In sum, the total funding cost for the government would be lower-owing to the lower real yield -if it could issue individual-specific indexed bonds.

In reality, however, making markets incurs non-trivial transaction costs, encompassing operational costs, search costs, and informational costs (due to adverse selection). So, to the extent that investors in indexed bonds value market liquidity, it may not be optimal to issue a large number of bonds indexed to individual-specific deflators. The optimal number of price indexes to use should be determined according to the usual principle of equating the marginal benefit (equal to the consumer welfare gain from introducing a new bond indexed to an additional price deflator) to the marginal cost (equal to the welfare loss due to the fall in market liquidity).

Changes in the yield on a TIPS issue on the day (and the following few days) when it loses its on-the-run status to a newly auctioned issue can give us some sense of the magnitude of the 
cost arising from a loss in market liquidity. ${ }^{40,41}$ According to Fleming and Krishnan (2009), there is surprisingly little difference in terms of bid-ask spread and quoted depth between on-the-run and off-the-run TIPS, despite the sharp drop in trading volume when a TIPS issue goes off-therun. ${ }^{42}$ There is, however, a substantial decline in the prevalence of a firm quote for both bid and ask. ${ }^{43}$ This is in contrast to the nominal Treasury market, where studies find that all three of the liquidity indicators show a major change-a sharp widening of bid-ask spreads and a rise in yield along with a drop in trading volume and prevalence-when securities go off-the-run (see, for example, Goldreich et al., 2005).

These results suggest that, at least conditional on the issuance volume to date, the marginal liquidity cost of introducing additional inflation-protected bonds may be somewhat modest, manifest mostly in the prevalence of two-sided quotes. On the other hand, caution must be applied in extrapolating the estimates of liquidity cost based on additional issuance of bonds indexed to the same price deflator to a case where the new bonds would be indexed to different deflators. For instance, liquidity cost could be highly convex and rise significantly faster in the latter case as the market became segmented. There could also be compositional changes in the investor base that alter the liquidity cost function. For example, if a higher fraction of retail investors were to buy and hold and thus place less value on liquidity, and if more of them would enter the market when multiple-deflator indexation allowed them to better hedge their specific inflation risk, then the cost for any given degree of liquidity loss could be lower.

By comparison, it is even harder to gauge the marginal benefit of introducing new bonds indexed to other consumer price indexes, in part because of data limitations. For instance, we lack adequate information about which financial institutions currently hold TIPS, let alone

\footnotetext{
${ }^{40}$ This is likely a cleaner measure of the marginal cost due to liquidity than the average yield spread between on- and off-the-run TIPS. For example, one factor complicating the latter comparison is the embedded protection of the original principal investment in TIPS. This option becomes relevant and is more in-the-money for new issues than for older ones when the expectation of deflation is non-negligible.

41 "On-the-run" status denotes the most recently issued U.S. Treasury bond or note of a particular maturity. When a new such security is issued, the former "on-the-run" issue becomes known as "off-the-run." There is more liquidity in the most recently issued securities than in the older issues with the same remaining time to maturity.

42 "... average daily volume plunges from $\$ 233$ million on the last day a security is on-the-run (that is, the auction day of the next security) to $\$ 45$ million the day after." whereas "Quoted bid-ask spreads average two to three 32nds for on-the-run and off-the-run 5- and 10-year notes..." (p. 10, emphasis added)

43 Prevalence drops from close to 60 percent to about 15 percent from the on- to the off-the-run 10-year note.
} 
characteristics of the households who are the underlying account holders. Furthermore, it can be as useful to know why some segments of the population, who theory would suggest are natural investors in TIPS, have low participation rates. For instance, suppose data showed that the majority of TIPS were held by institutions such as pension funds and insurance companies to hedge liabilities indexed to the CPI, yet individuals with low balances of such indirect claims held only small amounts of TIPS. There could still be substantial benefit from expanding the choice set of price indexes for inflation protection if the main reason those individuals did not participate was because their ideal price index differed sufficiently from the CPI that they were unwilling to pay the premium to compete with institutional investors. Alternatively, if the lack of participation were merely a symptom of the fact that such individuals generally have little savings, then there might be little benefit from indexing to additional price deflators.

A related question is whether to also expand the universe of issuers of inflation-protected real bonds. In particular, should state and local governments issue bonds indexed to the cost of living specific to their region? This may be an outcome that raises social welfare on net if the heterogeneity in inflation is driven more by components that differ along the geographic dimension, such as housing cost and, more generally, commodities that are more difficult to trade-a primary example being services - than by non-geographic factors. For instance, if a state government's revenue is positively correlated with state-wide prices of services because both depend positively on the state's economy, then it may be a natural hedge for the state government to issue bonds indexed to the within-state price deflator. Individuals could benefit from such issuance to the extent that such indexes better reflect their idiosyncratic consumption bundles.

On the other hand, such state or local bonds clearly suffer from diminished liquidity, as discussed above. Experience in the existing market for municipal bonds can provide some guidance on the degree of liquidity demanded by typical investors in such instruments. Furthermore, one may discover that favorable tax treatment similar to that enjoyed by municipal bonds may be necessary to entice investors to purchase and hold state-indexed bonds. In fact, even with the tax advantage, it is likely that only large states, or municipalities with sufficiently distinct local living costs, such as New York, would find adequate demand for 
real bonds indexed to specific local costs of living. Another factor to consider, as recent history has demonstrated, is that municipalities have credit risk that can be quite varied and is certainly greater than that of the U.S. Treasury.

\subsubsection{Are there better aggregate price indexes for inflation hedging?}

We now explore whether any of the other aggregate price indexes are better than the CPI for inflation protection. It is likely more feasible to index bond returns to any of these deflators than to introduce detailed price indexes for sub-sections of the population. Since our focus is on protection against inflation for consumers, we restrict our attention to the other members of the CPI family (that is, CPI-W, CPI-E, and chained CPI) and the Personal Consumption Expenditures (PCE) deflator. We base our analysis on non-seasonally adjusted data for all these series, since only non-seasonally adjusted (NSA) data are available for the chained CPI. This should have minimal effect on our results because we compute the growth rate of each index by comparing its current value with its year-ago value (that is, its value 12 months ago for these monthly series). Judging by the series for which both seasonally adjusted and NSA data are available, seasonal adjustment indeed seems to make little difference. ${ }^{44}$ Last, for comparison, we also consider the GDP deflator because it is used widely.

The CPI-W is the price index for urban wage earners and clerical workers. It covers a subset of the urban population but is in fact the oldest among the CPI series. ${ }^{45}$ Social security benefits are indexed to the CPI-W. It differs from the CPI-U only in the expenditure weights used to aggregate the item-level price indexes. The weights differ most for the following spending categories: the CPI-W population spends more on transportation, more on tenant rent, and less

\footnotetext{
${ }^{44}$ For instance, non-seasonally adjusted data for the CPI-U and CPI-W start as early as 1921, while seasonally adjusted data start in 1947. Over the years 1947 to 2008, that is, when both SA and NSA data are available, the growth-rate differential and the correlation between these two price indexes are essentially the same for SA and NSA data.

${ }^{45} \mathrm{CPI}-\mathrm{W}$ covers urban "households for whom 50 percent or more of household income comes from wages and clerical workers' earnings." In particular, it "excludes households of professional and salaried workers, part-time workers, the self-employed, and the unemployed..." This group's share in the overall population has diminished over the years. (The BLS CPI Manual, p. 2).
} 
on owner-equivalent rent. ${ }^{46}$ But even the biggest weight difference is less than three percentage points. So it is not surprising that the time series of the CPI-U and the CPI-W have nearly the same sample mean inflation rate: the former on average rises faster by less than 0.1 percentage point since 1983. Their growth rates are also highly correlated (Figure 6 and Table 2.) ${ }^{47}$ More importantly, regressions (see the first four rows of Table 3) show that the difference in the inflation rates of the two indexes does not covary significantly with any of the three commonly used aggregate risk factors. ${ }^{48}$ This means that, for those consumers who (for whatever reason) want to hedge the inflation risk as specifically measured by the CPI-W, indexing to the CPI-U does not expose them to systematic risk.

The CPI for the elderly (or CPI-E) is an experimental price index for Americans 62 years of age or older. The BLS first reported its CPI-E calculations to Congress in 1988, and in 1994 extended the series back to 1982. The CPI-E rose slightly faster than the regular CPIs-a faster pace that averaged 0.3 percentage point per year over the common sample period 1982-2007. Stewart (2008) explains that this was mainly due to the faster than average inflation of medical care and shelter costs, both of which account for a greater share in the CPI-E. On the other hand, CPI-U and CPI-E are also highly correlated (Figure 7 and Table 2).

If we suppose that the CPI-E should, in principle, be a more accurate index for retirees than the regular CPIs, then for hedging purposes retirees should note that the difference in the two inflation rates is not significantly correlated with any of the three aggregate risk factors. This is the case for the full sample (beginning in January 1983) as well as for the more recent subsample (beginning in January 1990), as shown in the last four rows of Table 3. This suggests that indexing TIPS to the CPI-U exposes retirees to little systematic risk. These calculations are, of

\footnotetext{
${ }^{46}$ For example, based on the 2003-2004 Consumer Expenditure Survey weights, the shares of spending on tenant rent, OER, and transportation are, respectively, 7.99 percent, 30.22 percent, and 20.37 percent for the CPI-W versus 5.92 percent, 32.47 percent, and 17.95 percent for the CPI-U. For more details, see the BLS CPI manual.

${ }_{47}$ We include in the table only results over the sample period that overlap with CPI-E. In terms of average inflation rate, the difference between CPI-U and CPI-W is, in fact, much smaller over the full sample (only 0.03 percentage point), and the correlation higher (0.998). The smaller difference may be because the availability of data in the early years precludes a finer distinction between the two indexes. For inflation hedging in the future, the behavior of these price indexes in recent decades is presumably more relevant.

48 Starting the sample in January 1983 enables matching with the sample for the CPI-E. The subsample that begins in January 1986 removes the early years, when the inflation difference was unusually large; as expected, this lowers the loading on the market return, although the coefficient is insignificant in both cases.
} 
course, rather uncertain, subject to possibly substantial measurement errors in the CPI-E. ${ }^{49}$ Nonetheless, to the extent that the measurement errors are uncorrelated with the market risk factors, the coefficient estimates should be unbiased.

The chained CPI for all urban consumers, or C-CPI-U, is the newest addition; it adopts chain weighting, the chief methodological recommendation of the Boskin Commission. As explained above, the chain-weighting methodology better mitigates substitution bias by also including in the index calculation the current-period expenditure shares, reflecting consumers' (optimal) purchase decisions in response to price changes. The C-CPI-U series starts in December 1999. As shown above, the C-CPI-U inflation rate is on average lower than the CPI inflation rate (Figure 4) by about 0.4 percentage point over the common sample period, although the difference between this inflation rate and the inflation rate implied by the CPI-U is uncorrelated with the three aggregate risk factors.

The PCE deflator is the price index constructed by the Bureau of Economic Analysis (BEA) to deflate the expenditures of the personal consumption sector as defined in the context of the U.S. National Income and Product Accounts (NIPAs); this sector includes households as well as nonprofit organizations serving households. The PCE deflator differs from the CPI along five dimensions: index formula, aggregation weights, scope, seasonal adjustments, plus some itemlevel price indexes. Table 4 outlines these differences. The exact contribution of each dimension to the difference between the inflation rates of the CPI and the PCE deflator varies from sample period to sample period. For the most recent years (2002:Q1 to 2007:Q2), analysis shows that almost half of the difference in these two indexes' average inflation rates can be attributed to the different index-number formulas, while the different relative weights more than account for the rest. (For details, see McCully et al. 2007.) 50 $^{50}$

It can be argued that the PCE deflator is superior to the CPI as a cost of living index. Above all, the PCE deflator's index-number formula-chain weighting with geometric mean of

\footnotetext{
${ }^{49}$ As emphasized in the BLS CPI manual, the CPI-E is merely a reweighting of item-level indexes underlying the regular CPI, using expenditure weights from households headed by a person 62 years of age or older, without recalculating the detailed indexes to represent the retail outlets and consumption items of older consumers.

${ }^{50}$ Fixler and Jaditz (2002) examined an earlier period-1992:Q1 to 1997:Q2 - and found that both the formula effect and individual item-level price effect led to a faster increase ( 0.2 percentage point per year on average) in the CPI relative to the PCE deflator, mostly offset by weight and scope effects.
} 
expenditure shares in adjacent periods-minimizes substitution bias and mitigates the bias due to new products. Second, it is based on more objective data of expenditure weights-actual spending versus survey responses. ${ }^{51}$ On the other hand, the scope of the PCE deflator for some services may be broader than necessary for inflation hedging purposes. Specifically, unlike the CPI, it covers not only consumers' out-of-pocket expenses but also spending by employers and the government (mostly related to medical care) on behalf of households. So, it is unnecessary for consumers to hedge, at least directly, the inflation risk for these items. However, there may well be an indirect need for hedging, to the extent that such expenses substitute for explicit compensation because employers view them as fringe benefits. ${ }^{52}$ Furthermore, these arguments are conditional on current law, and consumers may want to implement partial hedges against the risk that some of these expenses may be "privatized" in the future.

In sum, owing to their application of chain weighting, both the C-CPI-U and the PCE deflator are relatively more accurate than the regular CPIs in capturing time variations in the cost of living, which is what matters for inflation protection. However, before we recommend issuing real bonds indexed to either index, we must balance the potential benefits against a common practical difficulty suffered by both indexes: current expenditure data become available with a lag, so the price index figures published in real time have to be revised over time as more complete data are gathered. This contrasts with the regular CPI data, which are never revised. Moreover, the average lag for the final release far exceeds six months, which is the typical interest payment frequency for indexed bonds. This introduces additional uncertainty for the secondary market pricing of such bonds: if the initial bond holders received interest first based on the preliminary index figure, and if that figure was subsequently revised and used to calculate subsequent interest payments, how would prospective buyers in the secondary market value the bond? And the index revisions may pose other practical problems as well for their secondary market trading. In fact, the difficulty of dealing with data revisions and delays is one of the traditional arguments put forth for why TIPS are indexed to CPI-U NSA

\footnotetext{
${ }^{51}$ This may be the reason why the shares of salient expenditure items, such as housing cost, are by comparison much higher in the CPI (where housing has a weight of around 42 percent in recent decades) than in the PCE deflator (where housing's weight hovers between 14 percent and 16 percent).

${ }^{52}$ Even the government's portion of these expenses may eventually affect tax rates and hence disposable income. This indirect risk would again call for partial hedging.
} 
and not to other indexes based on the national accounts, such as the PCE or GDP deflator, although in principle one could always just index the security to the preliminary, real-time release figures and ignore the revisions when calculating the coupon.

Last, we compare the CPI with the GDP deflator. Unlike the price indexes we have discussed so far, the GDP deflator has a much broader scope: as the name suggests, it is the implicit deflator for overall GDP, which encompasses not only consumption but also investment, government current expenditures and investment, and net exports. Since the mid1980s, prices on consumption items (that is, the items included in the PCE deflator) have tended to increase faster than prices on investment items, while the implicit deflator for government purchases tracked the PCE deflator closely until 2001 (Figure 8). ${ }^{53}$ On the whole, the GDP deflator and the PCE deflator have, in fact, had rather similar rates of inflation over the long haul, as well as since 1983 (Table 2). Among all the alternatives to the CPI-U considered here, the GDP deflator inflation has the lowest correlation with CPI-U inflation. At the same time, the PCE deflator is as correlated with the GDP deflator as it is with the CPI-U (Table 2).

In summary, our analysis indicates that differences across the available aggregate price indexes related to consumption seem minor in terms of the impact on inflation risk hedging. So, to the extent that there is non-negligible liquidity loss stemming from "fragmenting" the market for inflation-protected bonds, on net it may be more sensible not to introduce additional price indexes for bond return indexation.

\subsubsection{Instruments for hedging inflation risk of durables}

As discussed above, the CPI concerns prices of items in consumers' consumption basket. This means that, when it comes to durables, the CPI does not consider the aspect of durables as long-lived assets and the attendant variations in their market values beyond the period when they were first produced. This distinction is most relevant for residential housing, since it is the longest lived among all consumer durables and its value constitutes the largest share of most

\footnotetext{
53 The implicit price deflators for exports and imports (not shown in the chart) follow trends similar to that of the investment deflator.
} 
households' net worth. To recap, the CPI covers the per-period consumption of the flow of services from housing capital. ${ }^{54}$

As we argue above, because of the conceptual difference between market prices of houses and the concept that owner's equivalent rent intends to measure, it is likely more efficient to offer separate instruments for consumers to hedge the risk of unexpected changes in house prices. Besides, house prices exhibit substantial heterogeneity across geographic regions. Hedging instruments tied to separate house price indexes for different regions then would offer households the means to achieve more precise hedging and to minimize basis risk. A prominent example of a market where this could be done is the futures contracts on S\&P/Case-Shiller Metro Home Price Indexes, or the forward contracts on the Residential Property Index 25-MSA Composite (RPX), which has recently experienced substantially more liquidity than the futures on the S\&P/Case-Shiller Metro Home Price Indexes. Most recently (June 30, 2009), the New York Stock Exchange Euronext (NYX) began trading two exchange-traded products based on the S\&P/Case-Shiller Composite-10 Home Price Index. According to the NYX, these products, named MacroShares Major Metro Housing Up Trust and Down Trust (with ticker symbols UMM and DMM, respectively), allow for leveraged investment in either the upward or the downward movement of house prices, with no issuer or counterparty credit risk.

Intuitively, the need for hedging short-to-medium-term house-price fluctuations should be the greatest for people who plan to substantially change the amount of housing in their asset portfolio in the near future. One such group is those who plan to become first-time home buyers in a few years, unless they can inherit the desired dwelling. The other group is those who plan to downsize or upsize their houses. For example, retirees tend to downsize and live off the proceeds from the sale. ${ }^{55}$ Unless there is sufficient inter-generational hedging, they are better off directly purchasing house price hedges than relying on a general price hedge. Yet another group is households who plan to move to an area with sufficiently different housing prices, or price movements.

\footnotetext{
54 The CPI's treatment of other consumer durables is, in fact, inconsistent with its treatment of housing: the CPI accounts for other durables by using their purchase prices and ignores any flow of services afterward.

${ }_{55}$ Reverse mortgage can, in principle, be a viable alternative, but so far that market has been plagued with frictions such as asymmetric information problems and therefore is too expensive an option for most households.
} 
On the other hand, note that many homeowners are naturally hedged against house-price fluctuations already. These are households who, for various non-housing-related reasons (such as family ties and job availability), have little intention or opportunity to move in the short-tomedium run. That is, formally, even large house-price fluctuations have little effect on the present value of these households' welfare, as they choose to consume their endowment of housing capital for a large number of periods due to various non-housing-related constraints. So, for such homeowning households, it is clearly not worthwhile to pay the transaction cost to separately hedge against house-price movements.

Just as for hedging consumption price inflation, it is worth considering whether state or local governments have a comparative advantage in issuing financial instruments tied to local residential real estate price indexes. For instance, since local governments' revenues depend positively on house prices, it seems a natural hedge for them to issue bonds indexed to local property prices.

\section{TIPS as a short- or long-run hedge against inflation risk}

The primary appeal of TIPS is their ability to allow investors to hedge against unexpected changes in the inflation rate. In this section, we document the extent to which investors have historically experienced ex post real returns that deviated substantially from expected returns. For investors who bought newly issued long-term Treasury notes during the 1970s and 1980s, and held the notes to maturity, these deviations were large and variable. Sharp increases in price inflation during the 1970s caught many investors by surprise, at times producing ex post negative real rates of return on long-term Treasury securities. The speed of the Volcker disinflation of the 1980s, along with the subsequent revelation of the Federal Reserve's ability and commitment to keeping the inflation rate low and stable, seemed also to surprise many and resulted in ex post Treasury real returns that were very high by historical standards. Buying a TIPS note at issue and holding the note to maturity locks in a real rate of return with certainty, and so eliminates this risk. 
The efficacy of TIPS in hedging against inflation risk is largely independent of the inflation measure used. Although, as discussed in the previous section, there are differences between the price indexes that might be most appropriate for different households, these differences are relatively small compared with historical differences between expected and actual CPI inflation over reasonably long horizons.

Unlike TIPS that are held to maturity, TIPS sold prior to maturity expose their holders to the risk of substantial capital gains or losses due to changes in real interest rates. We show that a strategy of holding a TIPS Note for a relatively short period of time prior to maturity is an ineffective means of hedging against changes in inflation over that time period. Over relatively short horizons, the volatility in bond prices due to fluctuations in real interest rates overwhelms the relatively small deviations between actual and expected inflation.

\section{IV.A Inflation and ex post Treasury yields}

The difference between expected (ex ante) real yields on long-term Treasuries at the time of issue and their ex post realized real returns provides one measure of the potential value of TIPS as a real-return hedge. In order to calculate this difference, one needs a measure of expected inflation to use in calculating ex ante expected yields. Figure 9 illustrates the ex post real annualized yields on 10-year Treasury notes and 1-year Treasury bills that were purchased at issue and held to maturity. The dates on the horizontal axis of the graph refer to the issue dates. The annualized rate of change in the CPI-U over one- and 10-year horizons, which are also shown in the figure, were used to convert the nominal Treasury coupon yields to real yields.

The most striking fact that emerges from the figure is that the era of high 10-year forward inflation rates coincides with very low, and often negative, ex post real yields on Treasury notes. This raises the question: to what extent were the low real yields anticipated at the time of issue, and to what extent were they due to deviations between expected and actual inflation over the 10-year holding periods? If TIPS, or other inflation-indexed bonds, had been issued during this period, investors could have avoided the risk of inflation's deviating from its expected path. However, because such bonds were not available, investors were exposed to inflation risk. 


\section{IV.B Expected and actual inflation over long horizons}

Most of the evidence points toward the low ex post real yields having resulted from higherthan-expected inflation. Figure 10 displays the annualized rate of change in the CPI-U over a 10-year forward horizon and a 5-year backward horizon, as well as several measures of expected inflation over a 10 -year forward horizon.

Three of the measures of expected inflation are based on surveys of economists who were asked to state their forecast of the average growth rate of the CPI over the next 10 years. One of the lines in Figure 10 splices data for 1979 through the first half of 1991 from the consensus forecast of the annualized increase in the CPI from professional forecasters surveyed by the Blue Chip Economic Indicators program with data from the fourth quarter of 1991 on from the Federal Reserve Bank of Philadelphia's Survey of Professional Forecasters. ${ }^{56}$ Another line in Figure 10 shows, for 1990 on, the mean responses of participants in the Federal Reserve Bank of Philadelphia's "Livingston Survey." 57

Unfortunately, survey data on forecasts of average inflation over the next 10 years are not available for years prior to 1979. For this reason, we supplement the survey-based data on expected inflation with a constructed 10-year-ahead expected inflation variable used in the Federal Reserve Board's FRB/US model. ${ }^{58}$ The FRB/US expected inflation variable is based on predictions from a regression of survey estimates of expected inflation on its lagged value, the long-term expected federal funds rate, four lags of the quarterly value of core inflation, the federal funds rate, and the gap between actual and potential output. As shown in Figure 10,

\footnotetext{
${ }^{56}$ The Blue Chip Economic Indicators and Survey of Professional Forecaster data are both drawn from the Federal Reserve Bank of Philadelphia's internet site:

http://www.phil.frb.org/research\%2Dand\%2Ddata/real\%2Dtime\%2Dcenter/survey\%2Dof\%2Dprofessional\%2Dforeca sters/historical-data/inflation-forecasts.cfm. See Croushore (1993) for a description of the Survey of Professional Forecasters.

${ }^{57}$ The "Livingston Survey" is conducted by the Federal Reserve Bank of Philadelphia, continuing a survey of business economists first conducted by the newspaper columnist Joseph Livingston. Twice a year, about 50 economists, drawn mostly from both financial and non-financial businesses, are surveyed regarding their forecasts of key macroeconomic variables. See Croushore (1997) for a more complete description of the Livingston Survey. Data from the survey are available through the Federal Reserve Bank of Philadelphia's Internet site:

http://www.phil.frb.org/research-and-data/real-time-center/livingston-survey/.

${ }^{58}$ See Brayton and Tinsley (1996) for an exposition of FRB/US.
} 
this variable tracks the survey measures of expected inflation quite well during the 1980s and 1990s. Although we cannot compare the constructed variable to survey measures for the 1960s and 1970s, the variable takes on sensible values. Inflation was relatively low and stable during the early 1960s, and the FRB/US 10-year-ahead expected inflation variable tracks past CPI inflation (shown as the 5-year trailing moving average of annualized CPI inflation rates) quite closely during this period. By the late 1960s, inflation had started to increase and the FRB/US 10-year expected inflation variable began a gradual ascent from slightly below 2 percent in the mid-1960s to nearly 8 percent in the early 1980s.

All of the expected inflation measures are largely backward-looking, moving with recent actual rates of inflation and often deviating substantially from the actual inflation rates that would be experienced over the subsequent 10 years. This is not surprising: although there was concern about the effect of an overheated economy on short-term inflation rates during the 1960s, it would have been essentially impossible at that time to forecast the oil shocks of the 1970s, or the response of the fiscal and monetary authorities to those shocks. Moreover, the notion of a vertical long-run Phillips curve was still controversial among economists during the late 1960s and 1970s. Even if professional forecasters had foreseen the oil shocks and policy responses, they likely would have underestimated the extent of the resulting increase in inflation.

As a result of the unforeseen shocks, and most likely also because of errors in forecasting the response of inflation to the shocks, the actual 10-year forward CPI growth rates were much larger than 10-year-forward expected inflation, starting in the mid-1960s. Figure 11 shows the difference between the FRB/US 10-year expected inflation variable and the actual 10-yearforward average CPU inflation rate. Forecasts of 10-year ahead average inflation rates increasingly underpredicted the subsequent actual experienced CPI inflation during the 1960s and early 1970s, with the underprediction of the average annual inflation rate exceeding 5 percentage points by 1972 .

During the 1980s, as the Volcker disinflation started to take hold, there was a great deal of uncertainty regarding both how quickly the change in policy regime would bring down the inflation rate and also whether the change in policy regime was permanent. Moreover, during 
the 1970s forecasters could not have predicted the regime change in Federal Reserve policy and the commitment of the Fed to low inflation rates, starting in the early 1980s. As a result, although actual 10-year inflation exceeded inflation forecasts during most of the 1970s, the forecast errors decreased starting early in the decade and by 1980 forecasts of annual inflation over the next 10 years exceeded the subsequent actual average annual inflation rate by approximately 2 percentage points. The overprediction of 10-year-forward average annual inflation peaked at above 3 percentage points before gradually decreasing, finally hitting zero in the mid-1990s.

It is important to recognize that the inflation expectations shown in Figure 10 reflect the expertise of business economists and professional forecasters. During the 1970s, actual annual inflation rates rose faster than economists' predictions of inflation over the subsequent 10 years, and then, during the 1980s, actual annual inflation rates fell faster than professionals' expectations of future inflation. It is possible that typical households, with less sophisticated views of the determinants of future inflation, had expectations of future inflation that moved more closely with short-term inflation rates. To the extent that this was true, these households would have made even greater errors than the professional forecasters in forecasting long-term inflation.

Section III discussed and documented differences among some of the price indexes available for the United States. Our conclusion that the differences across the available indexes are relatively minor in terms of the impact on inflation-risk hedging is reinforced when one examines average annualized inflation rates over 10-year horizons. Figure 12 shows the average annualized inflation rates for the CPI-U, the CPI-E, the PCE deflator, and four regionspecific versions of the CPI. Also shown is the 10-year-out expected average inflation rate variable from FRB/US. As expected, the 10-year average inflation rates based on different indexes all follow the same general path: increasing during the 1960s and early 1970s, and then starting a long period of decline through the mid-1990s. The difference between any one of the various 10-year-out inflation rates and the FRB/US expected inflation variable is generally much larger, and less predictable, than the differences among the average inflation rates based on different price indexes. 
This fact argues strongly in support of the value of TIPS as a real-return hedge. A priceindex-linked bond provides a means of hedging against swings in inflation caused by supply shocks or changes in policy. As long as the price indexes largely move together in response to shocks, it matters more that a price-index-linked bond is available than which specific price index is picked for the link.

\section{IV.C Short and long holding period returns}

The large divergence between expected and actual inflation over 10-year horizons suggests that the low realized real rates of return on 10-year Treasury notes purchased in the 1960s and early 1970s and held to maturity was due to unexpected increases in inflation. Figure 13 shows both the ex post and ex ante real yields on 10-year Treasury notes; the CPI-U was used to convert nominal yields to ex post real yields, and the FRB/US 10-year expected inflation variable was used to convert nominal yields to ex ante real yields. Although the ex post real yield fluctuates widely, swinging from negative values for Treasury notes that were issued in the early 1970s to exceeding 10 percent for notes issued in the early 1980s, the ex ante real yield stays within a much narrower range. The ex ante real yield is elevated during the periods of uncertain fiscal and monetary policy during the late 1960s and early 1980s, but otherwise is contained within a fairly tight band.

This suggests that TIPS, had they been available, would have been a very useful means of hedging against inflation risk during the 1960s through 1980s. Although Treasury notes had essentially no default risk, they exposed investors to considerable inflation risk. TIPS essentially allow investors to equate the ex post return with the ex ante return, thus avoiding inflation risk if the note is held to maturity.

If a TIPS note is not held to maturity, the investor is no longer guaranteed a fixed real rate of return. Fluctuations in the yield on newly issued TIPS result in changes in the prices of existing securities, exposing investors to capital gains or losses. In practice, this exposure implies that holding TIPS for short periods of time is a very ineffective hedge against inflation risk. Figure 14 compares the real rate of return from purchasing a nominal Treasury security six years 
before it will mature and then selling it a year later with the real return from buying a 1-year Treasury bill at issue and holding to maturity. ${ }^{59}$ The return from holding a TIPS security for a single year (starting six years before it will mature) is also shown for years in which TIPS were available. ${ }^{60}$ Figure 15 shows the same information, but only for the latter part of the sample, when TIPS were available.

Figures 14 and 15 show, as expected, that the ex post real return to holding a long-term Treasury security for a single year is much more variable than the real return to holding a 1year Treasury bill. The risk associated with changes in nominal long-term interest rates is substantial. Perhaps somewhat surprisingly, the real return from holding a TIPS security for a single year is nearly as variable as the return from holding a nominal Treasury security for a single year.

During much of the period shown in Figure 15, actual movements in the CPI were reasonably close to expectations (Figure 16 compares the expected year-ahead CPI inflation rate from the Survey of Professional Forecasters with the actual realized CPI annual inflation rates for the same period), although there are temporary divergences due to unexpected movements in energy prices and business cycle effects. In principle, an inflation-indexed bond could be used to hedge against unexpected changes in the inflation rate such as these. However, holding a long-term TIPS note for a relatively short period of time does not provide the desired protection. The wide fluctuations in the ex post real 1-year holding period return for TIPS reflect capital gains and losses due to changes in the coupon yield of newly issued TIPS. The same shocks that produce unexpected changes in inflation are also likely to affect the coupon yield on new TIPS issues, making the short holding period strategy an ineffective means of hedging against short-term inflation fluctuations.

\footnotetext{
59 The return to holding a 10-year Treasury note for one year was calculated using the formula (equation 10.1.4) given by Campbell, Lo, and MacKinlay (1996) and the zero-coupon equivalent yields of Gurkaynak, Sack, and Wright (2007). Gurkaynak, Sack, and Wright's data are available at: http://www.federalreserve.gov/pubs/feds/2006/200628/200628abs.html. The change in the CPI-U was used in converting the nominal return to an ex post real return.

${ }^{60}$ Zero-coupon equivalent yields derived by Gurkaynak, Sack, and Wright (2008) were used in calculating the singleyear holding period return; their data are available at: http://www.federalreserve.gov/pubs/feds/2008/200805/200805abs.html.
} 


\section{IV.D Are TIPS an effective hedge against inflation risk?}

Buying a newly issued TIPS and then holding it to maturity is an effective way to lock in a risk-free real rate of return. Although, as documented in Section III, there are important differences across price indexes, the changes in the inflation rate based on the CPI-U are highly correlated with inflation rates based on other price indexes over long periods. So, TIPS provide very effective protection against unanticipated changes in the average inflation rate over fairly long horizons. If TIPS had been available during the 1970s and 1980s, they would have been a very effective means of locking in a real rate of return. In contrast, long-term nominal Treasury issues produced unexpectedly erratic rates of return.

One caveat is that TIPS can provide protection against only a fraction of inflation for taxable investors. The inflation compensation of TIPS is taxable on individual federal returns. This is essentially no different from the tax treatment on nominal bonds, since the inflation premium component of nominal interest payments is also taxed. TIPS are not tax disadvantaged relative to nominal bonds, but investors are protected against only $(1-t)$ of inflation, where $t$ is the investor's federal marginal income tax rate. Of course, the investor receives full inflation protection if TIPS are held in a tax-preferred account, such as a 401(k).

Holding TIPS for a relatively short period is not an effective means of hedging against shortterm fluctuations in inflation. The question of whether the CPI-U is the most appropriate price index is more important in a short-run context than in a long run context, because inflation rates based on different price indexes will generally diverge in less predictable ways in the short run than in the long run. Moreover, investors looking to hedge against short-term inflation fluctuations may be trying to ensure that they can make a particular purchase in the future, such as intermediate inputs for a business or a college education for their children; thus, changes in the relative prices of these purchases may be of particular concern to such investors..

The most appropriate and useful role for TIPS may be for life-cycle saving by individuals and their agents. As the proportion of retirees who have defined-benefit pensions continues to decrease, the need for individuals to manage lump-sum accounts to provide a steady stream of real income during their retirement becomes more difficult. A "ladder" of TIPS with maturities 
linked to the dates when money will be needed for expenses is a safe investment well suited to retirees and those approaching retirement. TIPS also have the potential to be the backbone asset underlying inflation-indexed life annuities. These are currently very rare, partly as a result of the financial literacy problems that plague the general immediate annuity market, but also because of the difficulty insurance companies face in hedging against long-term inflation risk. Individuals may spend 30 or more years in retirement, so extending the maximum duration of TIPS would likely help to improve the functioning of the indexed life annuity market.

\section{Conclusion}

Through a variety of means, we show that the efficacy of TIPS in hedging against inflation risk is, for the most part, independent of the inflation measure used. In particular, many measures of inflation, including those based on regions or designed for the elderly, move together, so that differences among these measures are swamped by the difference between any of these measures and any survey-based measure of expected inflation. The difference between expected real yields - as measured by the nominal Treasury return less the expected inflation rate-and realized real returns - as measured by the nominal Treasury return less the actual inflation rate-provides one measure of the value of TIPS as a hedge against inflation fluctuations. We also show that TIPS as indexed to the CPI are at least as good as TIPS indexed to other measures of inflation, since the correlation between the implied inflation basis risk and common risk factors is neither economically nor statistically meaningful. Inflation basis risk arising from mismeasurement of the CPI is also uncorrelated with common risk factors, suggesting that the concern on the part of the popular press that such mismeasurement leaves TIPS investors poorly hedged against inflation risk is unfounded. We emphasize that buy-and-hold investors are hedged best, and that investors who buy and hold long-maturity TIPS are better hedged than investors who hold short-term TIPS maturities. The same shocks that generate unexpected changes in inflation will alter the coupon yield on new TIPS issues, so the short holding period strategy becomes an ineffective hedge against short-term inflation fluctuations. We also explain that TIPS-implied break-even inflation rates are not the same as inflation expectations and 
hence are not necessarily good measures of inflation expectations. As a result, they are also unlikely to be good forecasts of future inflation.

Finally, we draw some implications for the design of the TIPS market and related financial institutions issues. We conclude that, as is, the TIPS market provides a good hedge against inflation risk and that from a cost/benefit perspective there seems little to be gained from indexing to other inflation measures-be they broader, such as the GDP deflator, or narrower, such as regional inflation measures or the CPI-E for the elderly. A "ladder" of TIPS, with maturities linked to when money is needed for expenses, would help investors in or near retirement hedge against their nominal expenses over time. TIPS have the potential to be the backbone asset underlying inflation-indexed annuities, but to facilitate these annuities, the maximum duration of TIPS would need to be extended. With respect to housing as an investment as opposed to a consumption good, there is room for alternative hedging instruments and they are currently available in the form of futures contracts on S\&P/CaseShiller Metro Home Price Indexes, or forward contracts on the Residential Property Index 25MSA Composite (RPX). 


\section{References}

Anderson, Nicola, Francis Breeden, Mark Deacon, Andrew Derry, and Gareth Murphy (1996), Estimating and Interpreting the Yield Curve, Chapter 8 Chichester, England: John Wiley \& Sons.

Anderson, Roger L. (1999), “The U.S. Experience”, Chapter 15 of Handbook of Inflation Indexed Bonds, ed. Brynjolfsson, John, and Fabozzi, Frank J., New Hope, PA : FJF Associates.

Bitsberger, Timothy, the then Deputy Assistant Secretary for Financial Markets (June 2004), “Treasury Debt Management," PowerPoint discussion at the Barclay's Investment Conference, available by following the link "Treasury Debt Management" here: http://www.ustreas.gov/press/releases/js1726.htm.

Boskin, Michael J., E. Dulberger, R. Gordon, Z. Griliches, and D. Jorgenson (1996), “Toward a More Accurate Measure of the Cost of Living," Final Report to the Senate Finance Committee from the Advisory Commission to Study the Consumer Price Index, December 4, 1996.

Boskin, Michael J., E. Dulberger, R. Gordon, Z. Griliches, and D. Jorgenson (1998), “Consumer Prices, the Consumer Price Index, and the Cost of Living," Journal of Economic Perspectives, Winter 1998, 12( 1):3-26.

Brayton, F. and P. Tinsley, ed. (1996), “A Guide to FRB/US,” Division of Research and Statistics, Federal Reserve Board of Governors.

Broda Christian (2004), “Consumer Price Index Biases and Their Impact on Policy," International Perspectives, 32, July 2004.

Brown, Craig and Anya Stockburger (2006), “Item Replacement and Quality Change in Apparel Price Indexes," Monthly Labor Review, December 2006, pp. 35-45.

Campbell, John Y., Andrew W. Lo, and A. Craig MacKinlay (1997), The Econometrics of Financial Markets, Princeton University Press.

Clinton P. McCully, Brian C. Moyer, and Kenneth J. Stewart (2007), "Comparing the Consumer Price Index and the Personal Consumption Expenditures Price Index," Survey of Current Business, November, p. 26--33.

Croushore, Dean (1993), "Introducing: The Survey of Professional Forecasters," Business Review, November/December 1993, pp. 3--15, Federal Reserve Bank of Philadelphia. 
Croushore, Dean (1997), “The Livingston Survey: Still Useful After All These Years,” Business Review, March/April 1997, pp. 1-12, Federal Reserve Bank of Philadelphia.

D'Amico, Stefania, Don Kim, and Min Wei (2008), “Tips from TIPS: The Information Content of Treasury Inflation-Protected Security Prices", Finance and Economics Discussion Series, 200830, Board of Governors of the Federal Reserve System.

Deacon, Mark, Andrew Derry, and Dariush Mirfendereski (2004), Inflation-Indexed Securities: Bonds, Swaps \& Other Derivatives, $2^{\text {nd }}$ edition. Chichester, England: John Wiley \& Sons Ltd.

Diewert, W. Erwin (1998), "Index Number Issues in the Consumer Price Index," Journal of Economic Perspectives, 12 (1), Winter 1998, pp. 47--58.

Dalton, Kenneth V., John S. Greenlees, and Kenneth J. Stewart (1998), "Incorporating a Geometric Mean Formula into the CPI," Monthly Labor Review, 121 (10), pp. 3-7.

Fixler, Dennis and Ted Jaditz (2002), "An Examination of the Difference Between the CPI and the PCE Deflator," Bureau of Labor Statistics working paper \#361.

Fleming, Michael J. and Neel Krishnan (2009), “The Microstructure of the TIPS Market," unpublished manuscript, available athttp://www.newyorkfed.org/research/conference/2009/inflation/Fleming Krishnan.pdf.

Goldreich, David, Bernd Hanke, and Purnendu Nath (2005), “The Price of Future Liquidity: Time-Varying Liquidity in the U.S. Treasury Market," Review of Finance 9, 1-32.

Gordon, Robert J. (2006), "The Boskin Commission Report: A Retrospective One Decade Later," International Productivity Monitor, 12, pp. 7--22.

Greenlees, John S. and Robert B. McClelland (2008), "Addressing Misconceptions about the Consumer Price Index," Monthly Labor Review, August, pp. 3-19.

Greenlees, John S. (2006), “The BLS Response to the Boskin Commission Report," International Productivity Monitor, 12, pp. 23-41.

Gross, Bill, June 2008, “Hmmmmm?” PIMCO Investment Outlook.

Gurkaynak, Refet S., Brian Sack, and Jonathan H. Wright (2007), "The U.S. Treasury Yield Curve: 1961 to the Present." Journal of Monetary Economics, 54(8): 2291-2304, November 2007.

Gurkaynak, Refet S., Brian Sack, and Jonathan H. Wright (2008), "The TIPS Yield Curve and Inflation Compensation," Finance and Economics Discussion Series Working Paper Series 2008-05, Federal Reserve Board. 
Hammond, P. Brett (1999). "Understanding the CPI," Chapter 10 of Handbook of Inflation Indexed Bonds, ed. John Brynjolfsson and Frank J. Fabozzi, New Hope, PA : FJF Associates.

Hernandez, Sandra, July 7, 2008 "TIPS Flunk Inflation Test, as Fuel, Food Overtake CPI," Bloomberg.

Johnson, David S., Stephen B. Reed, and Kenneth J. Stewart (2006), "PriceMeasurement in the United States: A Decade after the Boskin Report," Monthly Labor Review, pp. 10-19.

Kan, William (1999), “Using Inflation-Indexed Securities for Retirement Savings and Income: The TIA-CREF Experience," Chapter 4 of Handbook of Inflation Indexed Bonds, ed. John Brynjolfsson and Frank J. Fabozzi, New Hope, PA : FJF Associates.

Kinney, Christopher F. (1999), “The Individual Investor and Inflation-Linked Bonds: Tax Issues and Retirement Planning," Chapter 19 of Handbook of Inflation Indexed Bonds, ed. John Brynjolfsson, and Frank J. Fabozzi, New Hope, PA : FJF Associates.

Kopcke, Richard W., and Ralph C. Kimball (1999), "Inflation-Indexed Bonds: The Dog That Didn't Bark," New England Economic Review, January/February 1999.

Lebow, David E. and Jeremy B. Rudd (2003). "Measurement Error in the Consumer Price Index: Where Do We Stand?" Journal of Economic Literature, Vol. 41, No. 1 pp. 159-201.

Noyer, Christian, Governor of the Bank of France (2004). “The Role of Inflation-indexed Bonds in the Process of Setting Monetary Policy: a Central Banker's Perspective," speech at the Morgan Stanley Seminar on Indexed Bonds, Paris, June, 9, 2004.

Phillips, Kevin P.(2008). "Numbers racket: Why the economy is worse than we know," Harper's, May 2008.

Poole, Robert, Frank Ptacek, and Randal Verbrugge (2005). “Treatment of Owner-Occupied Housing in the CPI," Bureau of Labor Statistics, on the Internet at www.bls.gov/bls/fesacp1120905.pdf

Roush, Jennifer E. (2008), "The Growing Pains of TIPS Issuance," Finance and Economics Discussion Series, 2008-08, Board of Governors of the Federal Reserve System.

Roush, Jennifer E., William Dudley, and Michelle Steinberg Ezer (2008), “The Case for TIPS: An Examination of the Costs and Benefits," Staff Report no. 353, October 2008, Federal Reserve Bank of New York. 
Sack, Brian, and Robert Elsasser (2004), “Treasury Inflation Indexed Debt: A Review of the U.S. Experience," Federal Reserve Bank of New York Economic Policy Review, May 2004.

Shelton, Allison (2000), "Inflation-Indexed Securities: Description and Market Experience," Public Policy Institute Research Paper, AARP.

Stewart, Kenneth J. (2008), “The Experimental Consumer Price Index for Elderly Americans (CPI-E): 1982-2007," Monthly Labor Review, Bureau of Labor Statistics, April, pp. 19-24.

"The Consumer Price Index," BLS Handbook of Methods, chapter 17, U.S. Bureau of Labor Statistics.

“The Inflation Protected (TIPS) Market.”(2005), Office of Debt Management, U.S. Department of Treasury, August 2005.

Triplett, Jack E. (2006), "The Boskin Commission Report After a Decade," International Productivity Monitor, Centre for the Study of Living Standards, vol. 12, pp. 24-60, Spring.

Triplett, Jack E. (2006). Handbook on Hedonic Indexes and Quality Adjustments in Price Indexes: Special Application to Information Technology Products, p. 259, Paris and Washington, D.C.: Organisation for Economic Co-operation and Development.

U.S. Bureau of Labor Statistics (1997), "Measurement Issues in the Consumer Price Index," June 1997, Response to the U.S. Congress, Joint Economic Committee.

U. S. Department of the Treasury, Federal Register, Appendix B to Part 356 of Title 31, "Sale and Issue of Marketable Book-Entry Treasury Bills, Notes, and Bonds (Circular, Public Debt Series 193). Available at:

http://ecfr.gpoaccess.gov/cgi/t/text/text-

$\underline{\mathrm{idx}}$ ? $=\mathrm{ecfr} \& \mathrm{sid}=14 \mathrm{a} 4 \mathrm{bda} 1931 \mathrm{f1e} 41 \mathrm{fe} 390 \mathrm{e} 60 \mathrm{fb} 40 \mathrm{~b} 944 \& \mathrm{rgn}=\mathrm{div} 5 \& v i e w=$ text\&node=31:2.1.1.2.51\&i $\underline{\mathrm{dno}=31 \# 31: 2 \cdot 1 \cdot 1 \cdot 2 \cdot 51 \cdot 4 \cdot 17 \cdot 7 \cdot 12}$

Verbrugge, Randal (2008). “The Puzzling Divergence of Rents and User Costs, 1980-2004," Review of Income and Wealth, Vol. 54, Issue 4, pp. 671-699. 


\section{Figures and Tables}

\section{Figure 1: Distribution of Competitive Auction Awards of 10-Year Treasury Notes}

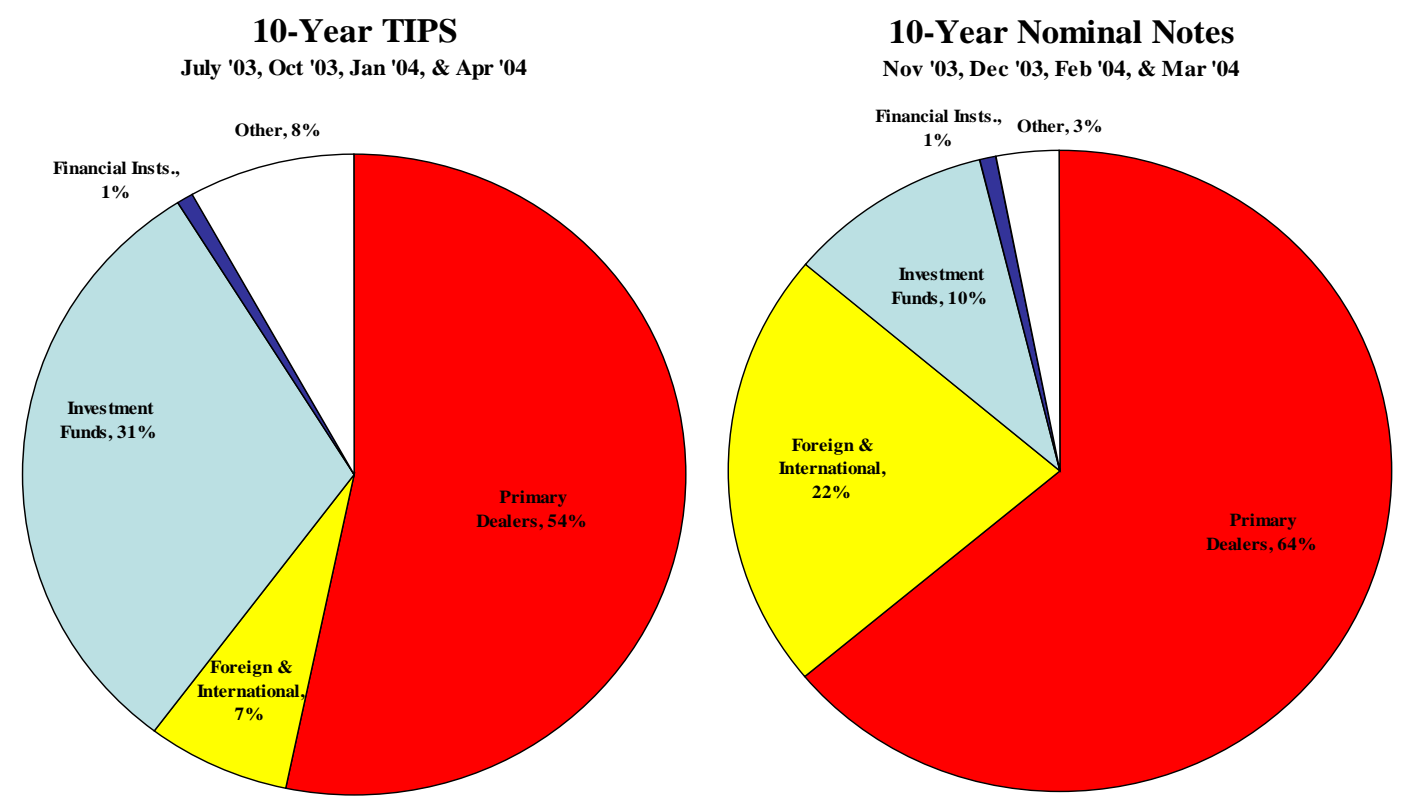

Source: June 2004 power point presentation by Timothy Bitsberger, then Deputy Assistant Secretary of Financial Markets for the U.S. Department of Treasury. Similar charts are available in various issues of the Treasury's Quarterly Refunding Charts and Data series.

Figure 2: Decomposition of the Nominal Yield into Inflation Compensation and the TIPS Yield*

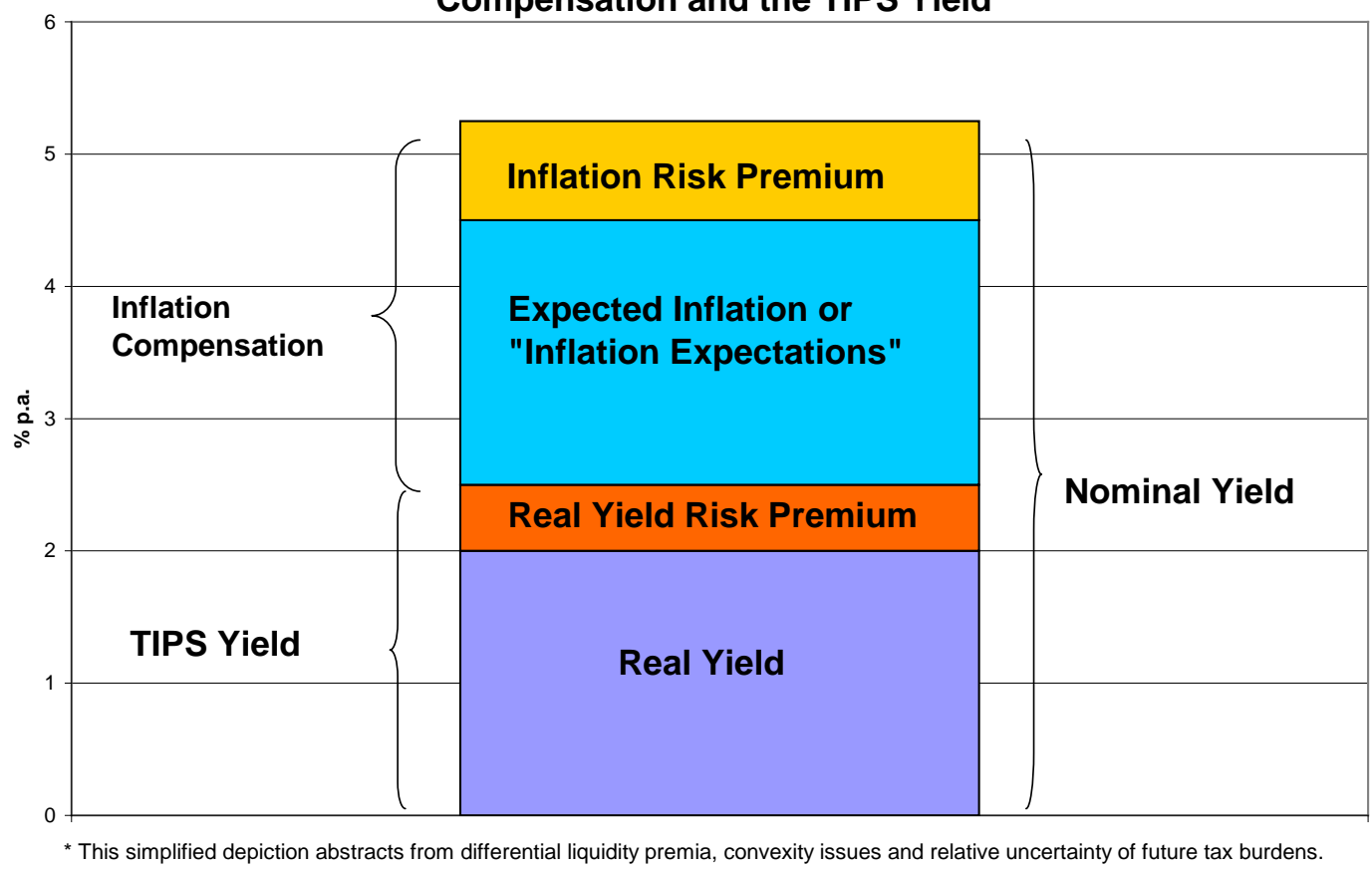




\section{Figure 3: Owners' Equivalent Rent in the CPI vs. House-Price Index}

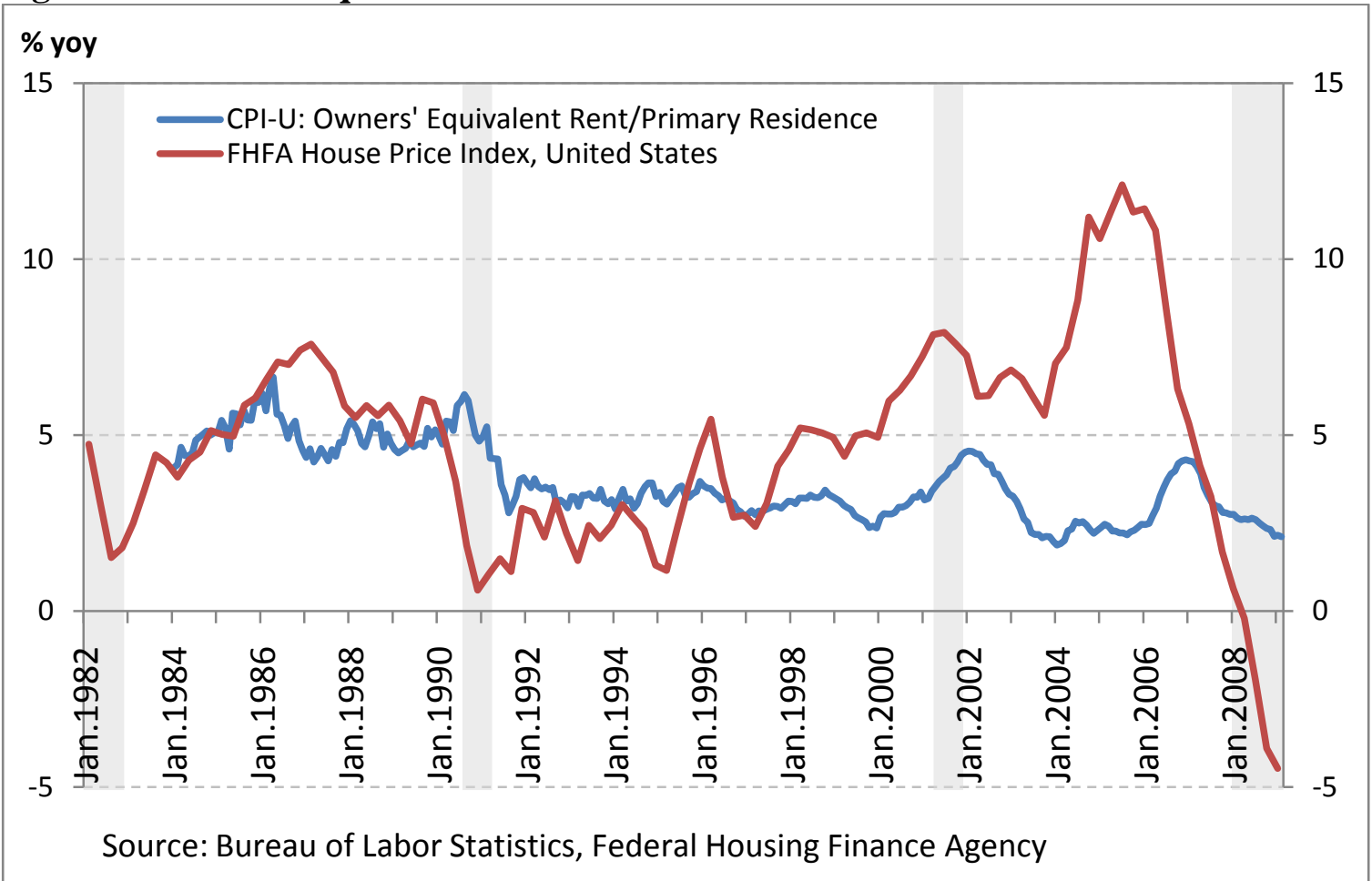

Note: The house-price index here includes refinancing. Results are qualitatively the same if we use the shorter time series of house-price index that is based on purchases only. 
Figure 4: Difference in Inflation Rates: Chained CPI-U vs. CPI-U

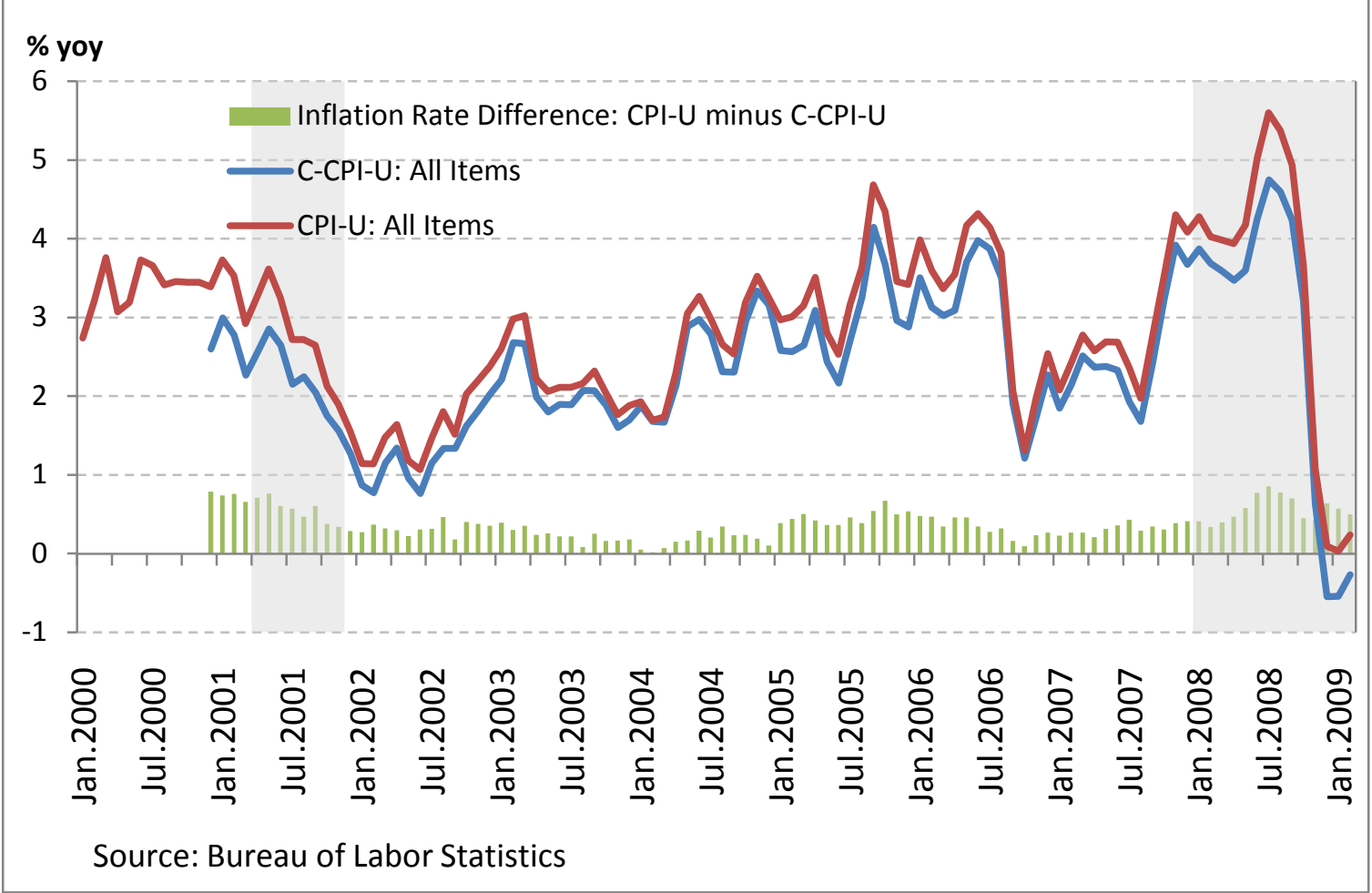

Figure 5: Inflation of Tenants’ Rent vs. Owners’ Equivalent Rent, and Household Energy Cost

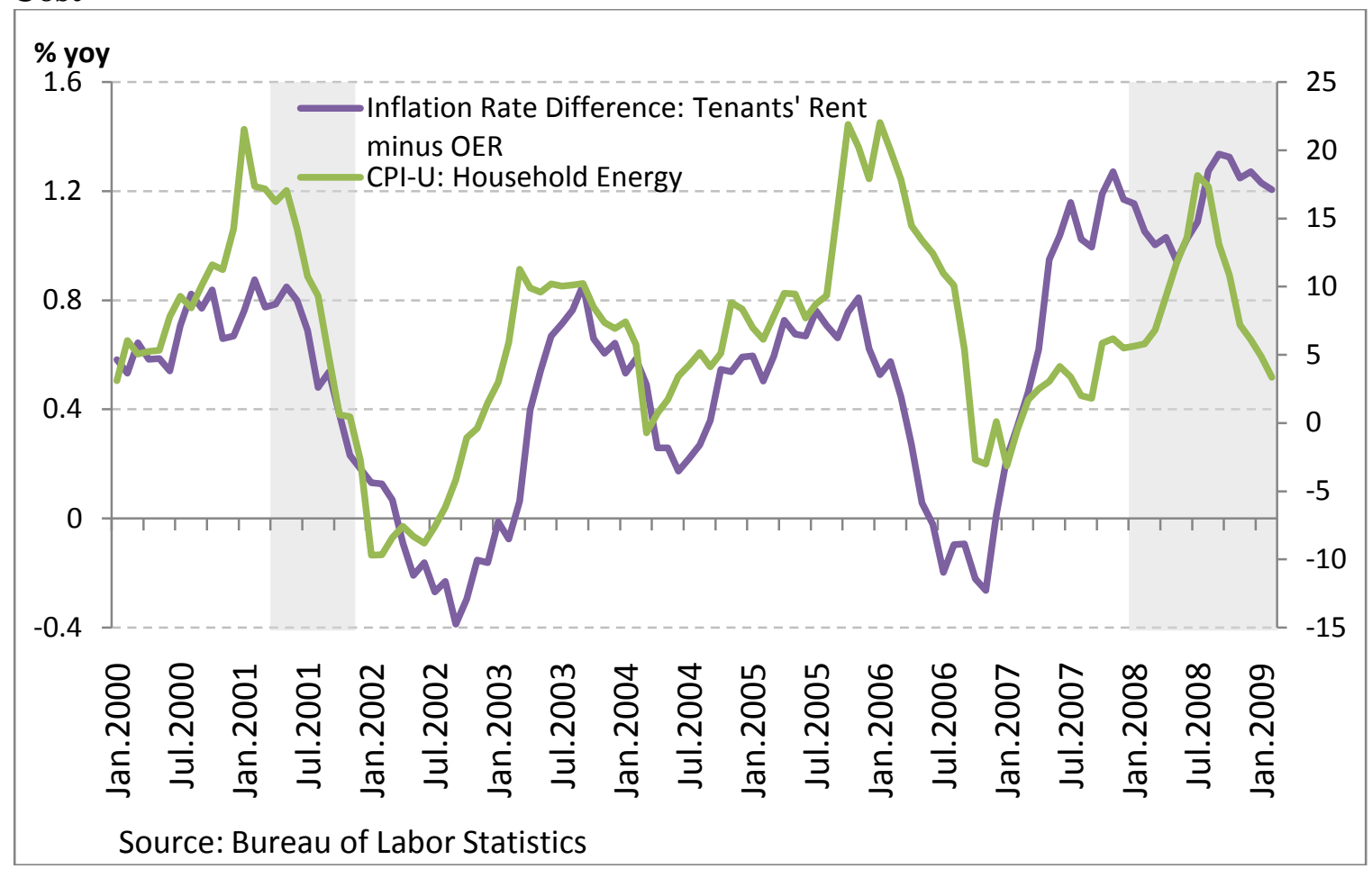


Figure 6: Inflation Rates: CPI-W vs. CPI-U

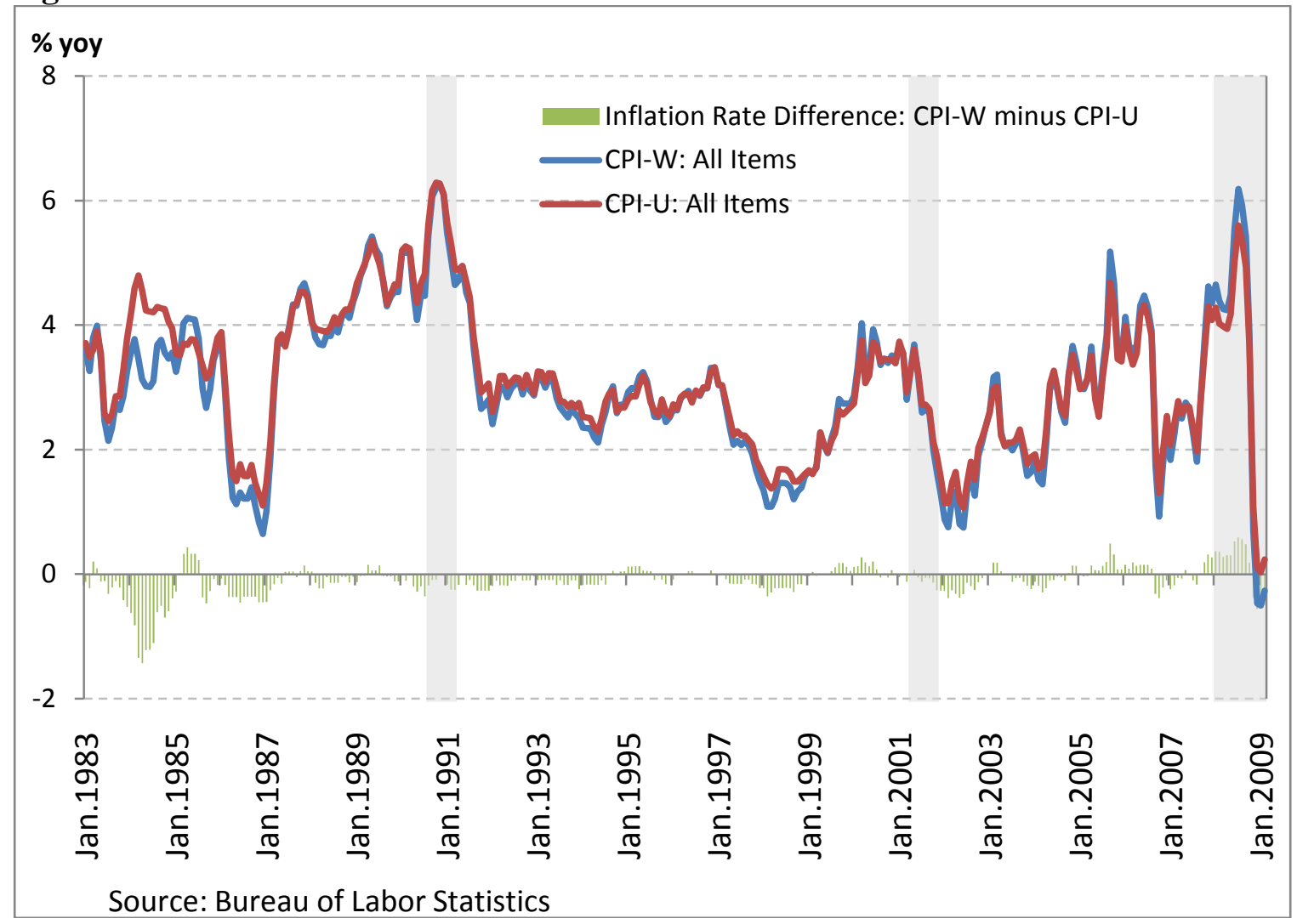

Figure 7: Inflation Rates: CPI-E vs. CPI-U

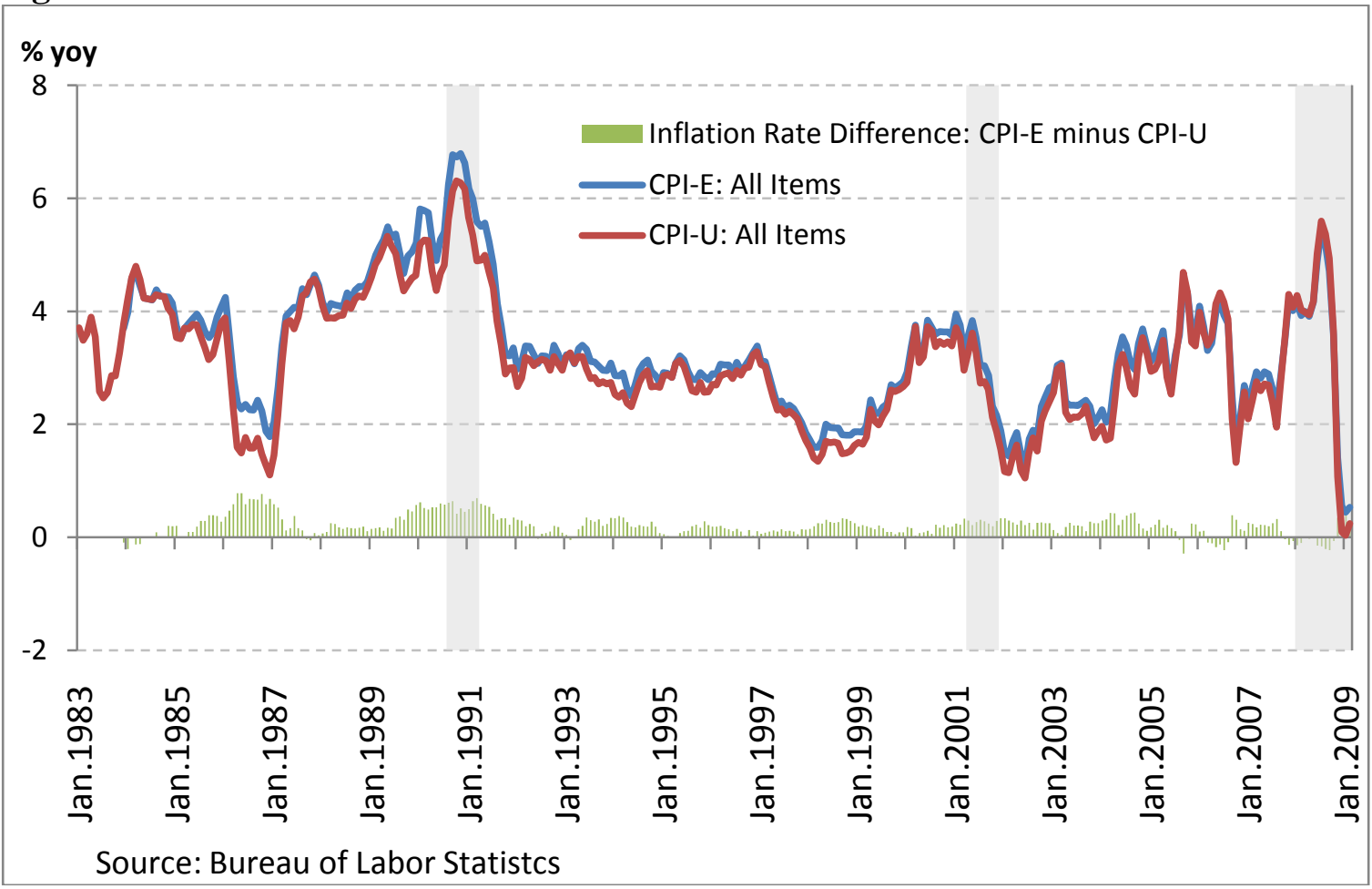




\section{Figure 8: Components of the GDP deflator}

Personal Consumption Expenditures: Chain Price Index $(S A, 2000=100)$

Private Fixed Investment: Chain Price Index (SA, 2000=100)

Government Consumption \& Gross Investment: Chain Price Index (SA, 2000=100)

Gross Domestic Product: Chain Price Index $(S A, 2000=100)$

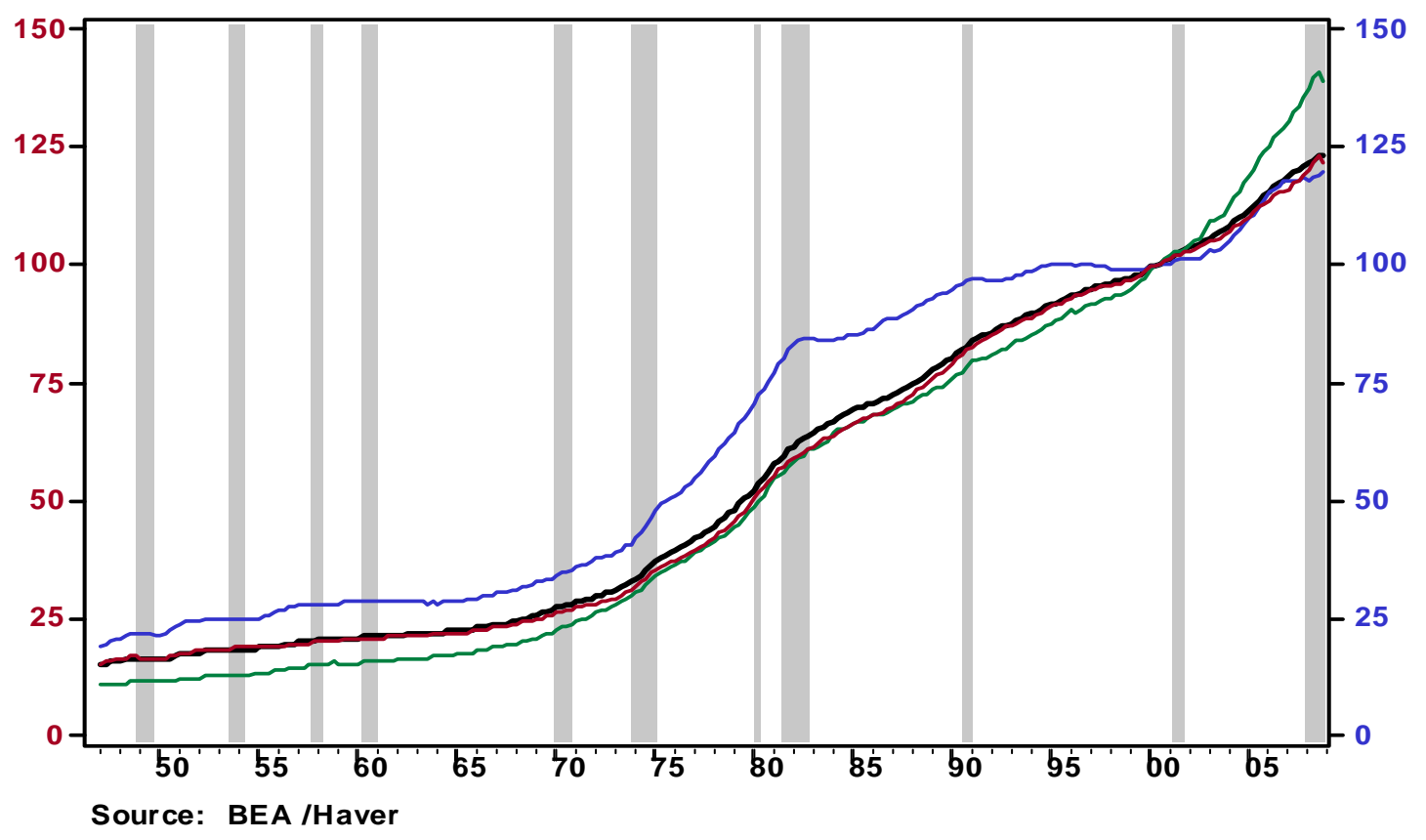

Figure 9: Ex Post Real Yields vs. CPI Growth

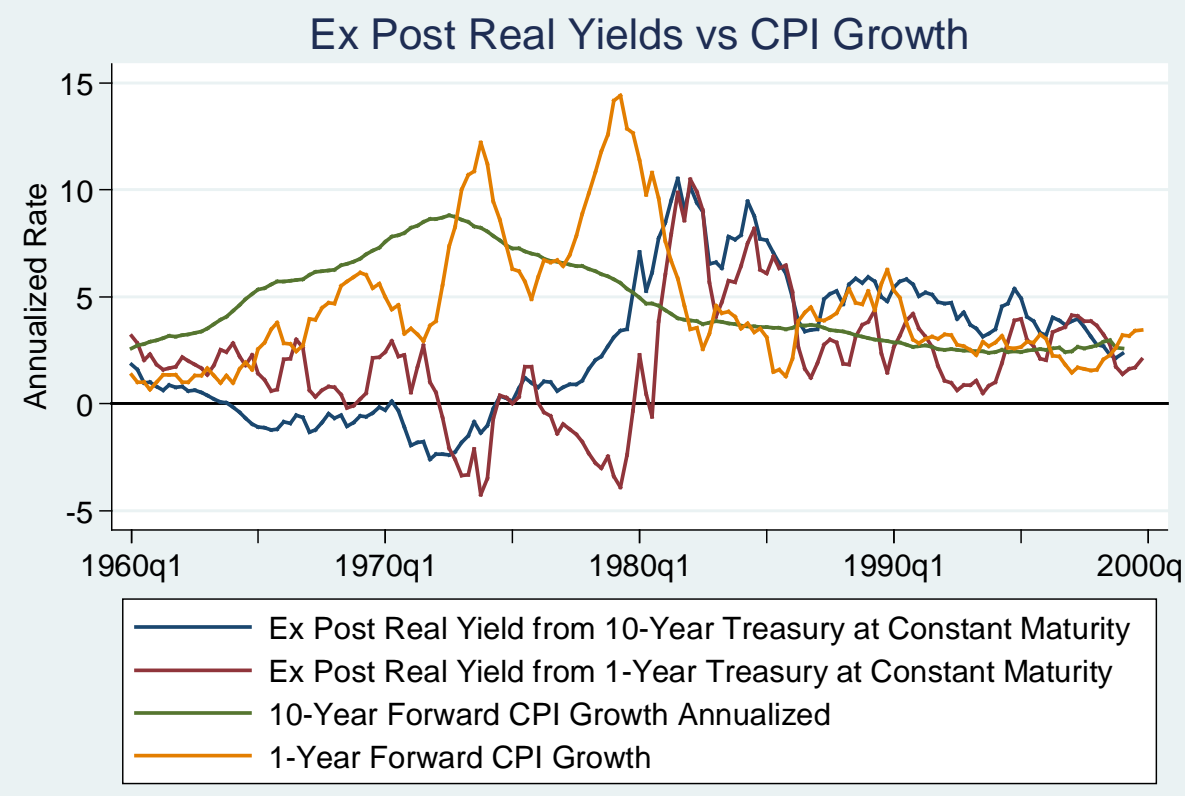

Source: Haver Analytics / Federal Reserve Board / Bureau of Labor Statistics 
Figure 10: 10-Year Forecast vs. Actual CPI Growth
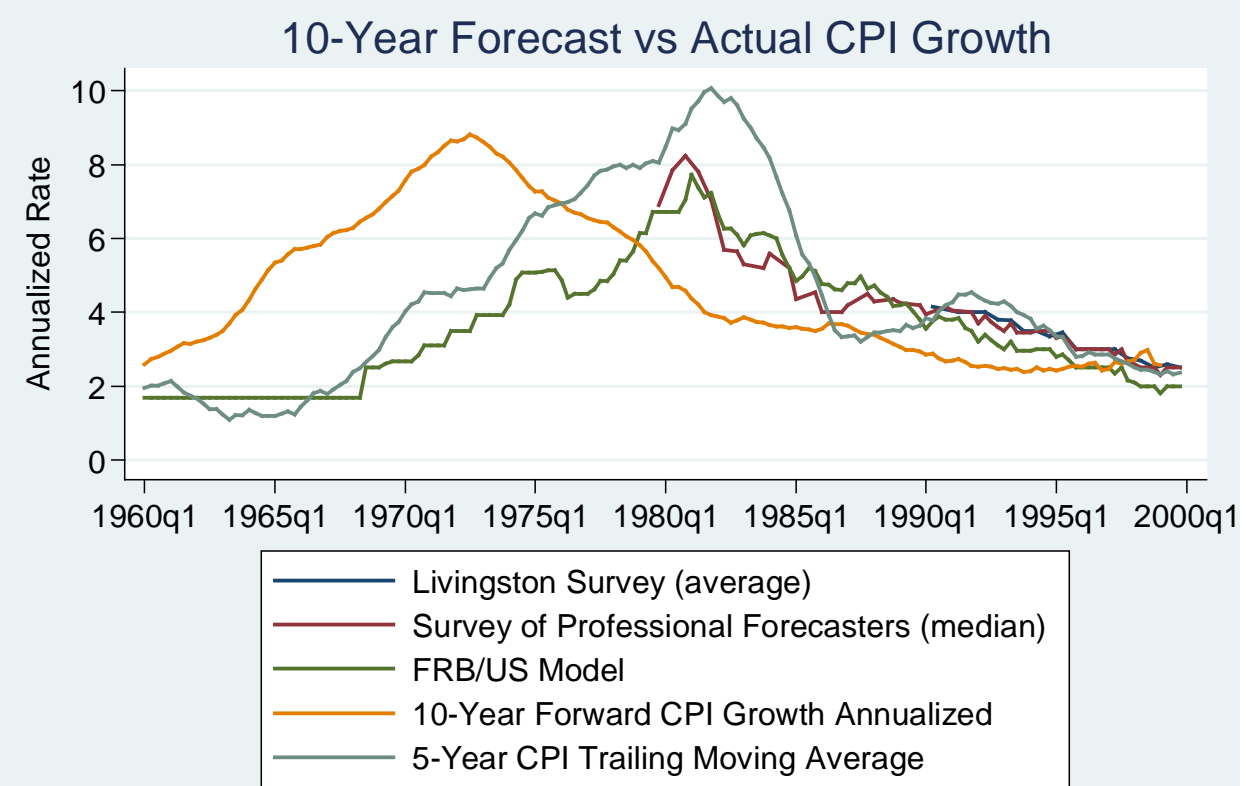

Source: Haver Analytics / Federal Reserve Board of Philadelphia / Federal Reserve Board / Bureau of Labor Statistics 
Figure 11: FRB/US Model Inflation Expectations Tracking Error

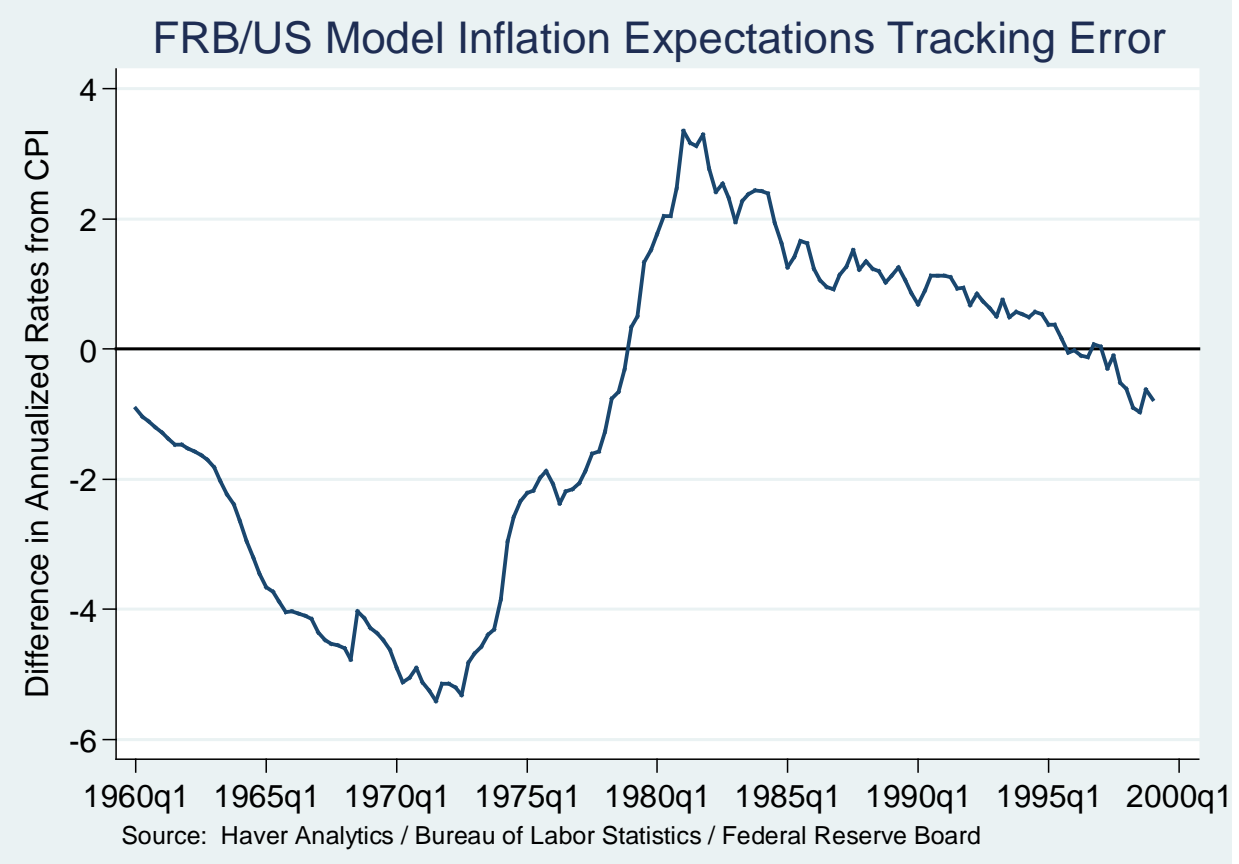

Figure 12: 10-Year Forward Growth Annualized in Price Indices

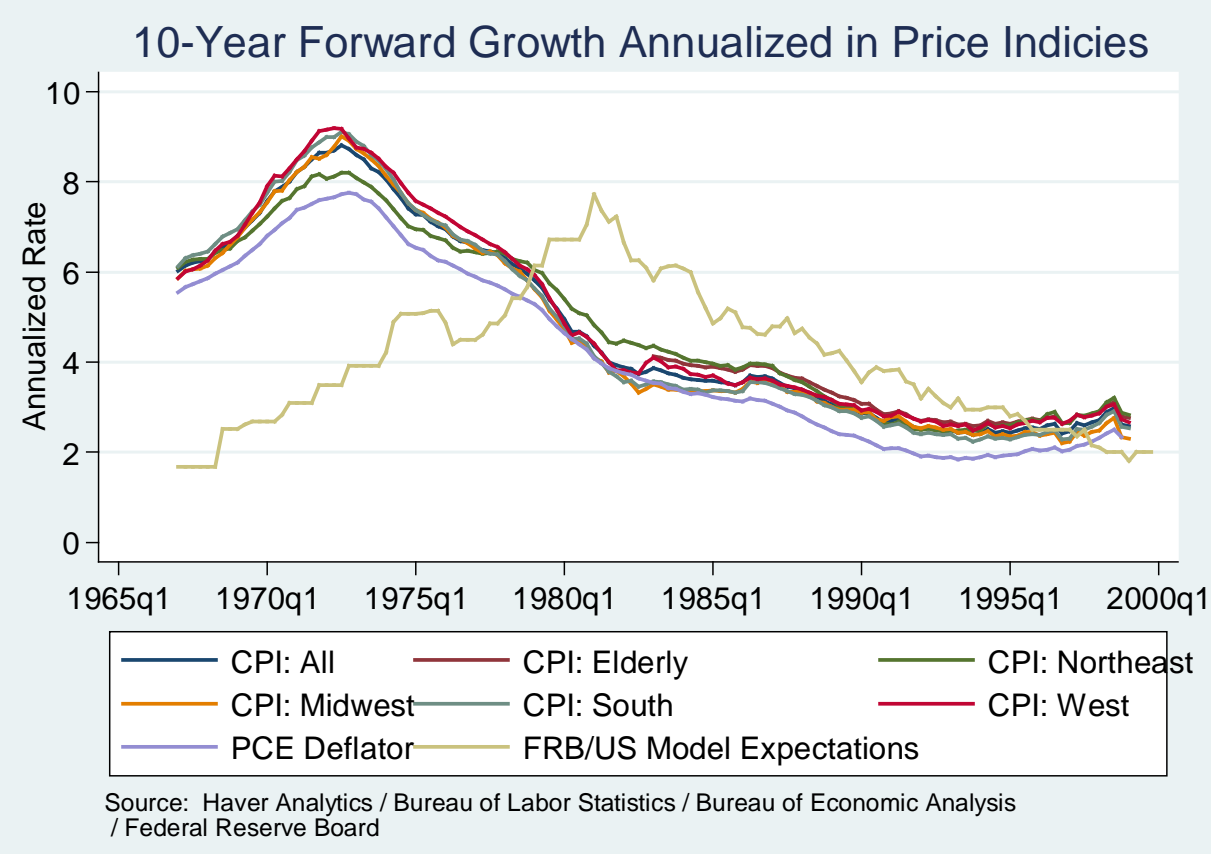


Figure 13: Ex Ante vs. Ex Post Real Yields
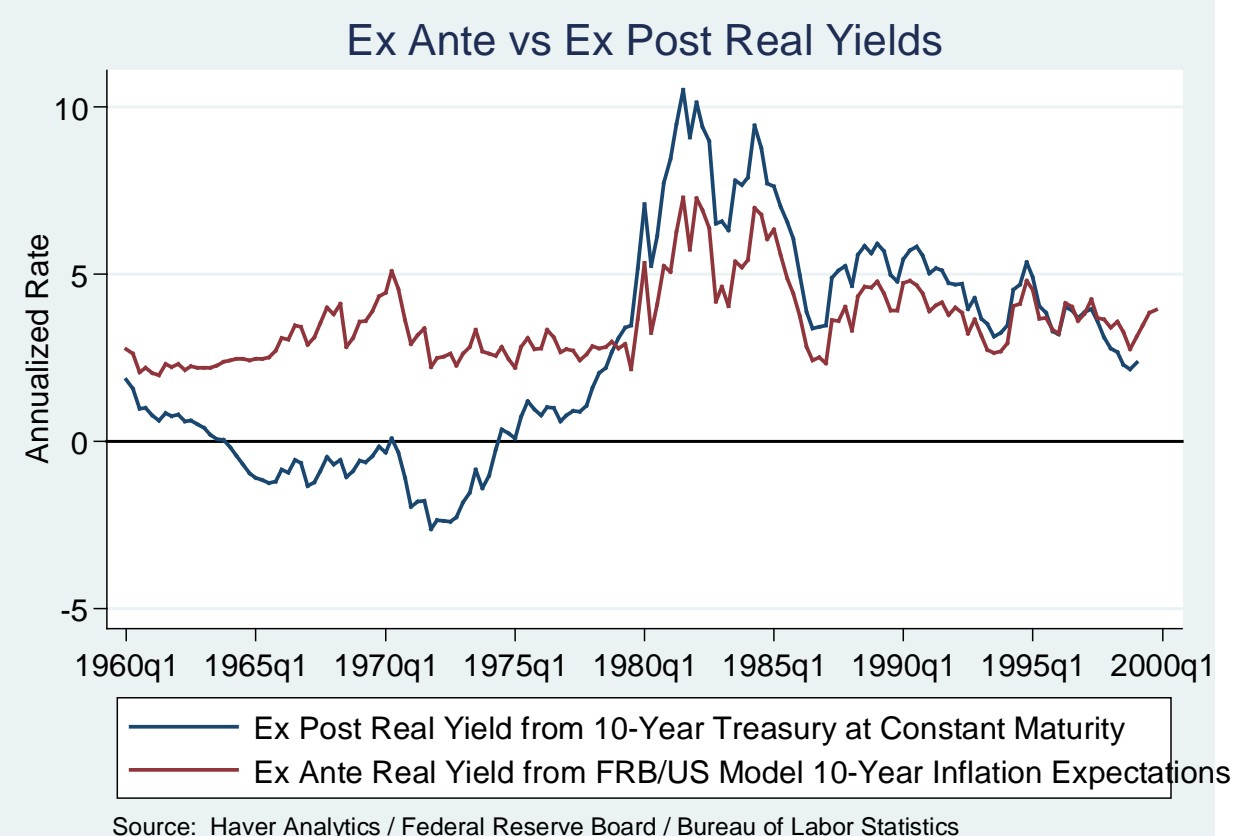

Figure 14: Real Holding Period Returns

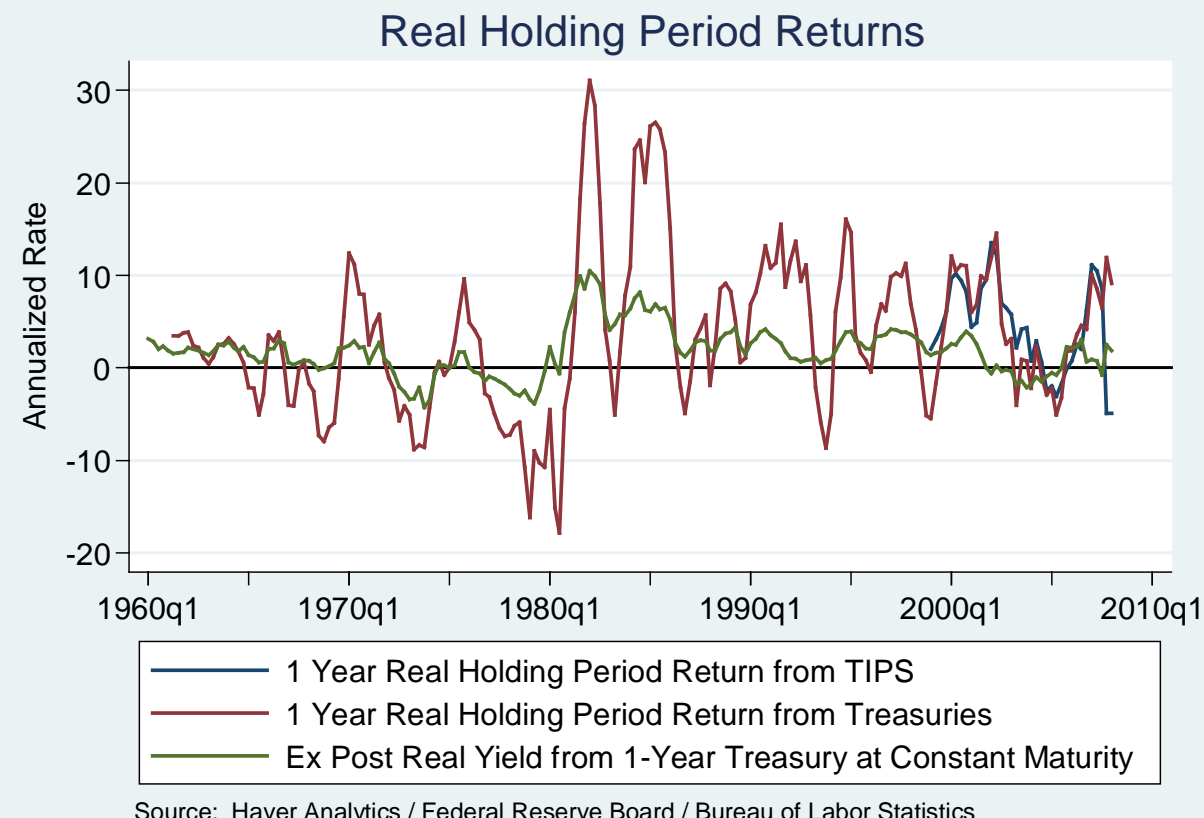


Figure 15: Real Holding Period Returns: 1999: Q1 to 2008: Q1

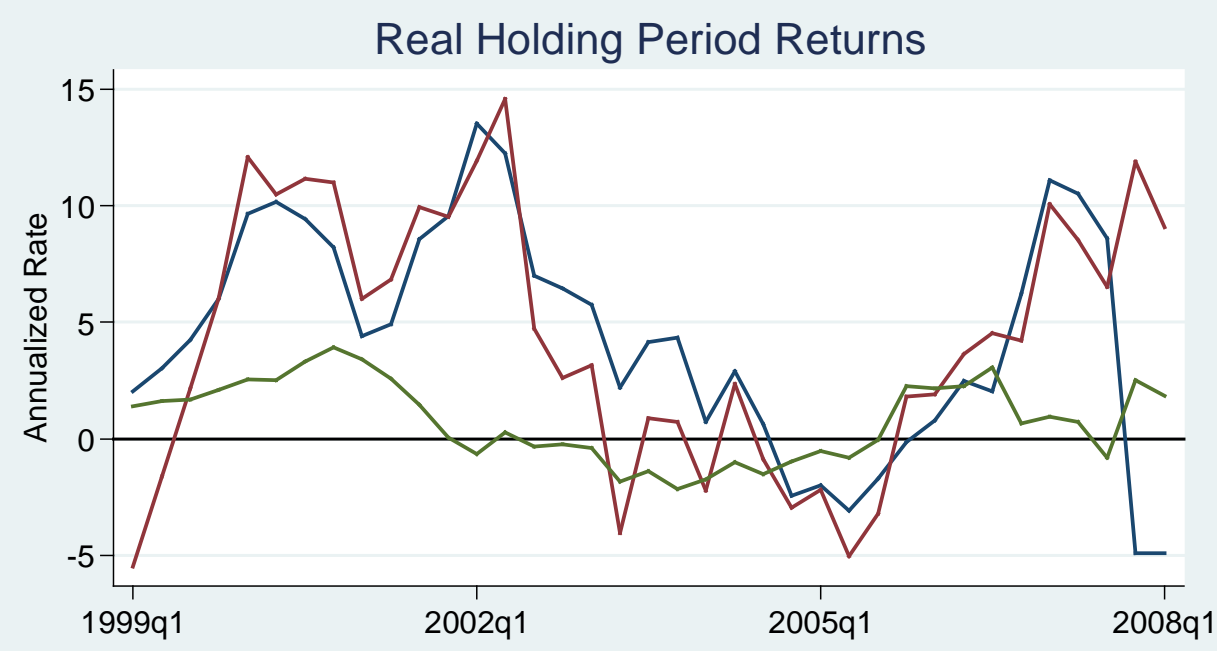

1 Year Real Holding Period Return from TIPS

1 Year Real Holding Period Return from Treasuries

Ex Post Real Yield from 1-Year Treasury at Constant Maturity

Source: Haver Analytics / Federal Reserve Board / Bureau of Labor Statistics

Figure 16: 1-Year Forecast vs. Actual CPI Growth

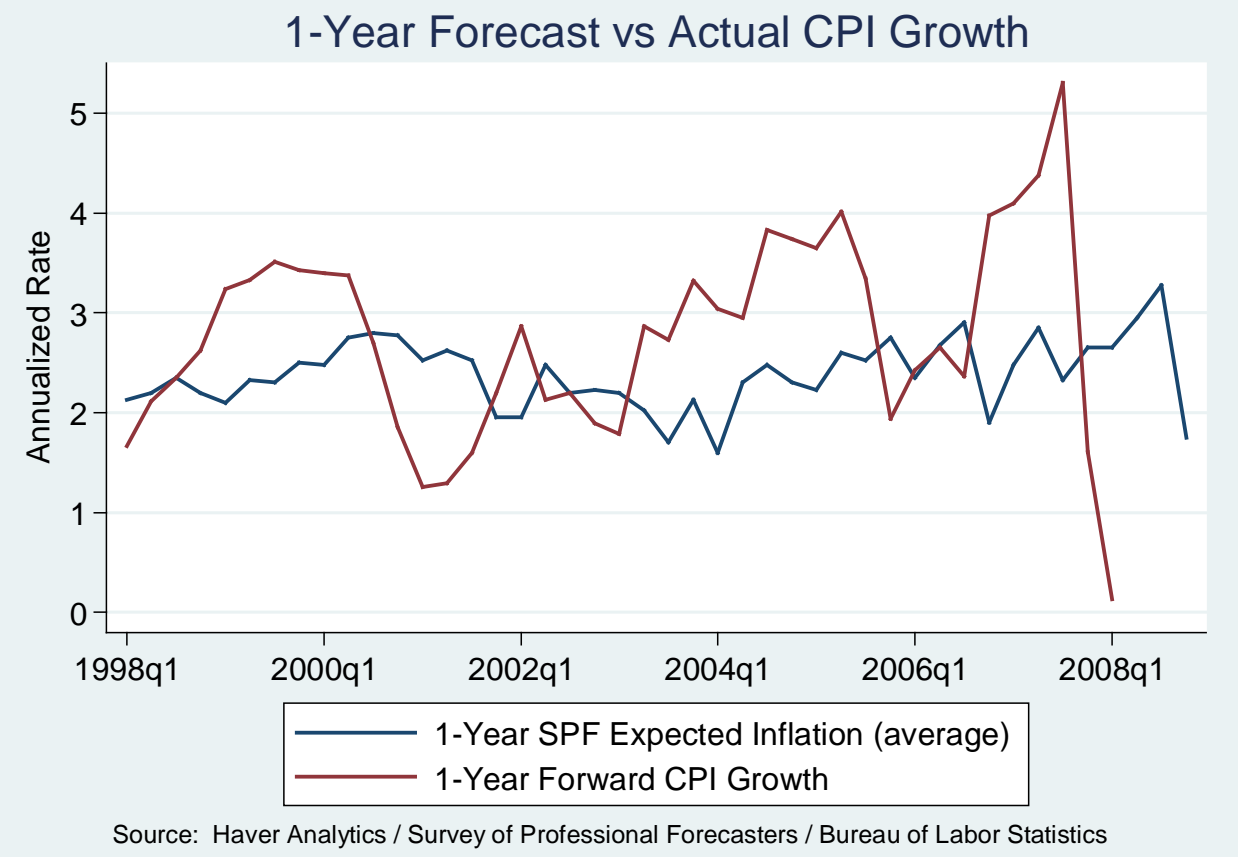


Table 1: Factor Loadings of the Remaining Substitution Bias in the CPI

\begin{tabular}{lccc}
\hline & Market Return & Fama-French SMB & Fama-French HML \\
\hline C-CPI-based Proxy & .0013 & -- & -- \\
& $(.0016)$ & & \\
& .0024 & -.0024 & .0024 \\
PCE-based Proxy & $(.0016)$ & $(.0021)$ & $-.0021)$ \\
& .0032 & -- & - \\
& $(.0013)$ & -.0022 & -.0043 \\
& -.0018 & $(.0021)$ & $(.0023)$ \\
\hline
\end{tabular}

Notes:

a. Standard errors are reported in parentheses.

b. All the regressions include a full set of month dummies.

Table 2: Comparison of Aggregate Price Indexes: Average Inflation Rate and Correlation

\begin{tabular}{lcccccc}
\hline & CPI-U & CPI-W & CPI-E & C-CPI-U & PCE Deflator & GDP Deflator \\
Sample Period & Dec. 1983-Feb. 2009 & Dec. 1983-Feb. 2009 & Dec. 1983-Feb. 2009 & Dec. 2000-Feb. 2009 & Dec. 1983-Feb. 2009 & Q1. 1983-Q4. 2008 \\
Avg. Inflation Rate* & 3.12 & 3.02 & 3.33 & 2.41 & 2.70 & 2.61 \\
Correlation: & & & & & & \\
CPI-U & 1.0000 & & & & & \\
CPI-W & 0.9788 & 1.0000 & & & & \\
CPI-E & 0.9860 & 0.9550 & 1.0000 & & & \\
C-CPI-U & 0.9856 & 0.9861 & 0.9794 & 1.0000 & & \\
PCE Deflator & 0.8939 & 0.8513 & 0.9408 & 0.9619 & 1.0000 & 1.0000 \\
GDP Deflator & 0.7410 & 0.8507 & 0.9382 & 0.9629 & 0.8863 & \\
\hline
\end{tabular}

*: Inflation rate is computed as rate of increase over 12 months ago.

Note: correlation coefficient with the C-CPI-U are all computed over the sample period Dec. 2000 - Feb. 2009. 
Table 3: Factor Loadings of the Alternative Aggregate Price Indexes to the CPI-U

\begin{tabular}{lccc}
\hline & Market Return & Fama-French SMB & Fama-French HML \\
\hline CPI-W & -.0019 & -- & -- \\
$(1983: 1-2009: 4)$ & $(.0011)$ & & .0002 \\
& -.0021 & $(.0016)$ & $(.0017)$ \\
CPI-W & $(.0012)$ & -- & -- \\
$(1986: 1-2009: 4)$ & -.0007 & & -.0007 \\
& $(.0009)$ & .0005 & $(.0015)$ \\
CPI-E & -.0010 & $(.0014)$ & -- \\
$(1983: 1-2009: 4)$ & $(.0010)$ & -- & .0013 \\
& .0009 & & $(.0015)$ \\
CPI-E & $(.0009)$ & -.0018 & - \\
$(1991: 1-2009: 4)$ & .0015 & $(.0014)$ & .0012 \\
& $(.0010)$ & -- & $(.0016)$ \\
\hline
\end{tabular}

Notes:

a. The dependent variable in each regression is the inflation rate difference between the CPI-U and the respective alternative price index.

b. Standard errors are reported in parentheses.

c. All the regressions include a full set of month dummies. 
Table 4: Comparison between the CPI-U and the PCE Deflator

\begin{tabular}{|c|c|c|}
\hline & CPI-U & PCE Deflator \\
\hline Index Formula & Laspeyres (fixed weights) & Fisher Ideal (chain weighting) \\
\hline Agency Responsible & BLS & BEA \\
\hline Price Data & Outlet surveys & $\begin{array}{l}\text { BLS price data (CPI \& PPI), } \\
\text { input-cost indexes, and others }\end{array}$ \\
\hline Expenditure Weights & Consumer Expenditure Survey & NIPA actual expenditure data \\
\hline Scope & Out-of-pocket expenses only & $\begin{array}{l}\text { All expenses related to the } \\
\text { household sector }^{1}\end{array}$ \\
\hline Others $^{2}$ & $\begin{array}{l}\text { Seasonal adjustments of } 73 \\
\text { selected CPI components; }\end{array}$ & $\begin{array}{l}\text { Seasonal adjustments of item- } \\
\text { level price indexes; different } \\
\text { price data for a few specific } \\
\text { CPI-comparable items }\end{array}$ \\
\hline
\end{tabular}

\footnotetext{
${ }^{1}$ : Includes both households' out-of-pocket expenses and expenses paid on behalf of households; the latter consists mainly of medical costs paid by employers and government (via various programs such as Medicare and Medicaid). ${ }^{2}$ : Other differences also include different revision schedules followed by the BLS for the CPI and by the BEA for the PCE deflator.

3: Specifically, the BEA uses an implicit deflator for passenger air transportation based on revenue and total miles traveled; the BEA also treats increases in gasoline price due to mandated pollution control as quality improvement, whereas the BLS treat such cases as price increases.
} 